\title{
Aqueous humor proteomic analysis of acute angle-closure glaucoma with visual field loss
}

\author{
Jiyu Xu ${ }^{1 \#}$, Liangliang Zhao ${ }^{2 \#}$, Xiang Liu ${ }^{1,3}$, Haidan Sun ${ }^{1}$, Xiaoyan Liu ${ }^{1}$, Zhengguang Guo ${ }^{1}$, Ying Wang ${ }^{2}$, \\ Wei Sun ${ }^{1}$ \\ ${ }^{1}$ Core Facility of Instrument, Chinese Academy of Medical Sciences, School of Basic Medicine, Peking Union Medical College, Beijing, China; \\ ${ }^{2}$ Department of Ophthalmology, The Second Hospital of Jilin University, Changchun, China; ${ }^{3}$ Shanghai AB Sciex Analytical Instrument Trading \\ Co., Ltd Beijing Branch Company, Beijing, China \\ Contributions: (I) Conception and design: J Xu, L Zhao; (II) Administrative support: W Sun, Y Wang; (III) Provision of study materials or patients: \\ Y Wang, L Zhao; (IV) Collection and assembly of data: All authors; (V) Data analysis and interpretation: J Xu, W Sun; (VI) Manuscript writing: All \\ authors; (VII) Final approval of manuscript: All authors. \\ "These authors contributed equally to this work. \\ Correspondence to: Wei Sun. Core Facility of Instrument, Chinese Academy of Medical Sciences, School of Basic Medicine, Peking Union Medical \\ College, 5 Dong Dan San Tiao, Beijing 100005, China. Email: sunwei@ibms.pumc.edu.cn; Ying Wang. Department of Ophthalmology, The Second \\ Hospital of Jilin University, 218 Ziqiang Street, Changchun 130041, China. Email: wangying9201@163.com.
}

Background: Acute angle-closure glaucoma (AACG) is an ophthalmic emergency that occurs over the course of hours or days and may cause irreversible blindness if not treated immediately. In most cases, optic nerve damage is the cause of visual field (VF) loss in AACG. There has been no reliable biomarker found to evaluate optic nerve damage to date. Aqueous humor $(\mathrm{AH})$ proteome analysis might reveal the proteomic alterations in AACG and provide helpful clues in the search for an AH biomarker of optic nerve damage and VF loss.

Methods: In this study, we used the AH proteome to explore the functions of differentially expressed proteins (DEPs) during disease progression. The AH proteins from the early-stage group and late-stage group were extracted and analyzed by the data-independent acquisition (DIA) method. The DEPs functions were annotated, and parallel reaction monitoring (PRM) was used to validate the key DEPs.

Results: A total of 87 DEPs were found. Gene Ontology analysis showed that most DEPs were enriched in immunology, hemodynamics, and apoptosis. Ingenuity pathway analysis found that vascular endothelial growth factor (VEGF) signaling, the production of reactive oxygen species (ROS) in macrophages, and the nuclear factor erythroid 2-related factor 2 (NRF2)-mediated oxidative stress response were active pathways in the late stage of AACG. The mechanism of retinal ganglion cell (RGC) death was hypothesized on the basis of DEP functional analysis. A total of 20 DEPs were validated by using PRM, and prostaglandin-H2 D-isomerase was found to have the potential to evaluate optic nerve damage.

Conclusions: This study showed that AH proteomic analysis could reveal the proteomic alterations in the pathogenesis of VF loss in AACG and help to provide objective protein biomarkers to evaluate VF loss. These findings will benefit the application of the AH proteome to clinical research.

Keywords: Aqueous humor (AH); proteome; acute angle-closure glaucoma (AACG); visual field (VF) loss

Submitted Jan 29, 2021. Accepted for publication Sep 03, 2021.

doi: $10.21037 /$ atm-21-457

View this article at: https://dx.doi.org/10.21037/atm-21-457

\footnotetext{
$\wedge$ ORCID: 0000-0001-8505-5104.
} 


\section{Introduction}

Glaucoma is a progressive optic neuropathy resulting in retinal ganglion cell (RGC) loss, optic nerve atrophy, and visual field (VF) loss (1). Acute angle-closure glaucoma (AACG) is an ophthalmologic emergency characterized by a rapid increase in intraocular pressure (IOP) due to an impaired outflow of aqueous humor (AH) (2). The incidence of AACG is usually higher among Asian populations (3). Reduced drainage leads to raised IOP, which potentially causes damage to the optic nerve (4). Despite adequate treatment, $3-12 \%$ of patients with acute angle closure develop long-term severe visual impairment, mainly as a result of glaucomatous optic neuropathy (4). Moreover, VF loss is not obvious under high IOP during acute AACG, and it progressively develops following acute AACG $(3,5)$. Glaucomatous optic nerve damage occurs due to RGC death (6). To date, many studies have pointed out that ocular hemodynamic changes and vascular pathological changes tend to cause optic nerve ischemic reperfusion injury, eventually resulting in $\mathrm{RGC}$ death $(7,8)$. Some molecules injure RGCs in various ways, one being nitric oxide (NO), which induces apoptosis and aggravates retinal damage. A high level of glutamate is also closely related to RGC death (9-11); however, a deep understanding of the RGC death mechanism in response to glaucoma is still lacking. Glaucoma patients can progressively and slowly develop optic nerve damage, even when IOP is well controlled (12). Biomarkers reflecting optic nerve damage could be of high clinical value. Optic nerve damage secondary to angleclosure leads to vision loss, and it has been traditionally determined by light microscopic evaluation of optic nerve cross sections (12). Currently, no reliable biomarkers have been found to evaluate optic nerve damage. Therefore, an improved molecular investigation may illustrate the relative changes in AACG and offer evidence for screening biomarkers.

The $\mathrm{AH}$ is an integral component in many ocular health functions, including nutrient and oxygen supply, removal of metabolic waste, ocular immunity, and ocular shape and refraction (13). The major constituents of $\mathrm{AH}$ are proteins (including proteins derived from the protein exchanges across the AH, vitreous fluid, retina, and optic nerve head), water, and electrolytes $(14,15)$. Although proteins in $\mathrm{AH}$ are present in relatively low concentrations compared to blood serum, they are vital for the maintenance of anterior segment homeostasis (15). Proteins secreted from anterior segment tissues play a role in various eye diseases, such as oedema, neovascularization, cataracts, and glaucoma (16-19). In glaucoma, elevated IOP causes damage to the optic nerve head (20), which may then release related components to reflect vitreous fluid (21); these then might be detected in $\mathrm{AH}$ via the vitreous-aqueous exchange. In this way, it may be possible to locate optic nerve damage biomarkers in the $\mathrm{AH}$ proteome. Technological advancements have allowed for high-throughput proteomic studies that examine biofluids such as $\mathrm{AH}$, vitreous humor, tears, and serum (15). A better understanding of the $\mathrm{AH}$ proteomic changes that occur during the development of eye diseases may provide clues in the search for $\mathrm{AH}$ biomarkers.

Previous studies have suggested that the AH proteome could reflect alterations in glaucomatous eyes. As early as 2010, Izzotti et al. reported AH proteome alterations in primary open-angle glaucoma (22). In 2016, Kliuchnikova et al. investigated 29 human AH samples from cataract and glaucoma patients with and without pseudoexfoliation syndrome. They identified 215 proteins in AH from glaucoma samples using high-resolution liquid chromatography with tandem mass spectrometry (LC-MS/ $\mathrm{MS}$ ) and found that $\mathrm{AH}$ proteins could reflect the neural origin of the eye; decreased apolipoprotein D was also defined as a marker of pseudoexfoliation syndrome (16). Kaeslin et al. defined 87 proteins that were differentially expressed between glaucomatous and control $\mathrm{AH}$, and the differentially expressed proteins (DEPs) were found to be involved in cholesterol-related, inflammatory, metabolic, antioxidant, and proteolysis-related processes (23). In 2019, Wang et al. analyzed the differential expression of $\mathrm{AH}$ proteins between acute primary angle-closure glaucoma (APACG) combined with cataracts and cataracts alone and found that the change in proteins in $\mathrm{AH}$ was related to the APACG (24). Previous studies have shown that the AH proteome could reflect proteomic changes in glaucoma and provide potential AH biomarkers. To our knowledge, AH proteome studies of VF loss in glaucoma are still unavailable. Therefore, in this study, we investigated the functions of $\mathrm{AH}$ proteins in VF loss in glaucoma by applying a proteomic strategy, with the greater aim of identifying biomarkers to assess optic nerve damage from AH proteins.

We obtained $\mathrm{AH}$ samples from early- and late-stage patients. The data-independent acquisition (DIA) method was performed to define the DEPs. The functions of the DEPs were annotated by Gene Ontology (GO) and ingenuity pathway analysis (IPA). Furthermore, parallel 


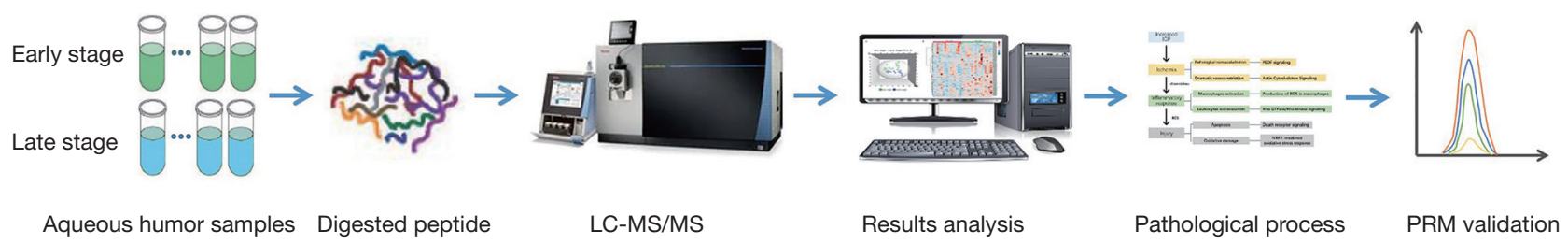

Figure 1 The workflow of this study. Permission was obtained from Thermo Fisher Scientific to use the image of Orbitrap Fusion Lumos Tribrid Mass Spectrometry. LC-MS/MS, liquid chromatography-tandem mass spectrometry; PRM, parallel reaction monitoring.

Table 1 The clinical information of the two cohorts

\begin{tabular}{lccccc}
\hline \multirow{2}{*}{ Characteristics } & \multicolumn{2}{c}{ Experimental group } & & \multicolumn{2}{c}{ Validation group } \\
\cline { 2 - 3 } \cline { 5 - 6 } \cline { 5 - 6 } & Late stage & Early stage & & Late stage Early stage \\
\hline Gender (F/M) & $14 / 2$ & $13 / 2$ & & $10 / 1$ & $9 / 1$ \\
Age (year) & 68.88 & 66.2 & & 69.36 & $61.20^{\mathrm{a}}$ \\
VFI & 14.10 & $93.53^{\mathrm{b}}$ & & 5.27 & $91.60^{\mathrm{b}}$ \\
IOP (mmHg) & 28.77 & 20.17 & & 24.67 & 29.33 \\
\hline
\end{tabular}

${ }^{\mathrm{a}}, \mathrm{P}<0.05$ for 2 stages; ${ }^{\mathrm{b}}, \mathrm{P}<0.001$ for 2 stages. VFI, visual field index; IOP, intraocular pressure.

reaction monitoring (PRM) was used to validate the key $\mathrm{AH}$ proteins. The goal of this study was to investigate the proteomic alterations in AACG and provide helpful clues for finding potential VF loss biomarkers in $\mathrm{AH}$ proteins. (Figure 1).

We present the following article in accordance with the MDAR reporting checklist (available at https://dx.doi. org/10.21037/atm-21-457).

\section{Methods}

\section{Ethical approval}

All volunteers were given a verbal explanation of the study before enrolment, and each participant signed an informed consent form. The consent procedure and the research protocol for this study were approved by the Ethics Committee for Human and Animal Research in Peking Union Medical College (No. 047-2019). The study methodologies conformed to the Declaration of Helsinki (as revised in 2013).

\section{Clinical information}

In this study, a total of 52 individuals were included and divided into 2 cohorts according to their visual field index
(VFI). The late-stage (LS) cohort included 27 AACG patients with a VFI lower than 50, and the early-stage (ES) cohort included 25 AACG patients with a VFI higher than 80 , according to the glaucoma staging system (25), where $\mathrm{VFI}>80$ indicates early stage, and VFI $<50$ indicates severe and end stage. The clinical information of the 2 cohorts is shown in Table 1 and Table S1. All AACG patients were on anti- \glaucoma medication with the same drugs (topical alpha receptor agonists, topical carbonic anhydrase inhibitors, topical beta-blockers, and systemic carbonic anhydrase inhibitors), and no patients had cataracts. The IOP was measured before glaucoma surgery, and there was no statistical difference between the 2 groups. The VFI data were also collected before surgery. The mean ages of all participants ranged from 60 to 70 years, and the age-related difference was not remarkable.

\section{Reagents and instruments}

Ammonium bicarbonate, dithiothreitol (DTT), formic acid, high-performance liquid chromatography (HPLC)grade acetonitrile (ACN), iodoacetamide (IAM), and trifluoroacetic acid were purchased from Sigma-Aldrich (St. Louis, MO, USA). Sequencing-grade trypsin was purchased from Promega (Madison, WI, USA).

An Orbitrap Fusion Lumos Tribrid Mass Spectrometer coupled with an EASY-nLC 1000 (Thermo Fisher Scientific, Bremen, Germany) was employed in the discovery phase.

A Triple TOF 5600 mass spectrometer (AB Sciex, Framingham, MA, USA) coupled with an ACQUITY UPLC system (Waters Corp., Milford, MA, USA) was used in the validation phase.

\section{Clinical materials}

All participants underwent an ophthalmic evaluation, including IOP measurement, VFI value measurement, best 
corrected visual acuity (BCVA) measurement, gonioscopy testing, and fundus examination. The inclusion criteria for AACG were as follows: most of the angle was closed, IOP was increased, and fundus changes and VF defects could be found in the glaucoma optic nerve injury. Patients with autoimmune diseases, malignant tumors, severe liver disease, and previous ocular surgery were excluded. The AH samples were obtained from glaucoma patients during surgery. Each sample was approximately 50-200 $\mu \mathrm{L}$ and was aspirated from the anterior chamber using a 26-gauge needle before the start of surgery. A total of $52 \mathrm{AH}$ samples were collected. These samples were randomly divided into 2 groups: the experimental group (31 samples: 15 from early stage and 16 from late stage) and the validation group (21 samples: 10 from the early stage and 11 from the late stage). After collection, the AH samples were immediately centrifuged at 2,500 $\times \mathrm{g}$ for 10 minutes at $4{ }^{\circ} \mathrm{C}$ to remove the cellular components (CC) and debris, and the supernatants were stored at $-80^{\circ} \mathrm{C}$ until further analysis.

\section{Protein extraction and digestion}

From each AH sample, $5 \mu \mathrm{L}$ was taken for a pooled sample. The pooled sample was used as quality control (QC) sample, which was injected frequently to monitor the reproducibility of the LC-MS/MS. The AH samples and the pooled sample were precipitated overnight using 3 times the volume of ethanol at $4{ }^{\circ} \mathrm{C}$. Then, the pellets were centrifuged at 10,000 $\times \mathrm{g}$ for 30 minutes and resuspended in lysis buffer (7 M urea, $2 \mathrm{M}$ thiourea, $0.1 \mathrm{M}$ of DTT, and $5 \mathrm{mM}$ of Tris; $\mathrm{pH}=8$ ). The protein concentrations of $\mathrm{AH}$ samples were determined by spectrophotometry based on the Bradford method.

The filter-aided sample preparation (FASP) method was used for protein digestion with trypsin. The protein samples $(200 \mu \mathrm{g})$ were deoxidized with $20 \mathrm{mM}$ DTT for $5 \mathrm{~min}$ at $95^{\circ} \mathrm{C}$ and carbamidomethylated with $50 \mathrm{mM}$ IAM for $45 \mathrm{~min}$ at room temperature in the dark. Then, the samples were digested with trypsin $(4 \mu \mathrm{g})$ in $25 \mathrm{mM}$ of $\mathrm{NH}_{4} \mathrm{HCO}_{3}$ buffer $(\mathrm{pH}=8)$ and incubated at $37{ }^{\circ} \mathrm{C}$ overnight. After digestion, the peptides were desalted with a $\mathrm{C} 18$ solid-phase extraction column (Waters Oasis, Dublin, Ireland), washed with $500 \mu \mathrm{L}$ of $0.1 \%$ formic acid, eluted with $500 \mu \mathrm{L}$ of $100 \% \mathrm{ACN}$, and then vacuum-dried.

\section{Offline HPLC}

The lyophilized peptide mixture was redissolved in
$0.1 \%$ formic acid, and a high-pH reversed-phase liquid chromatography (RPLC) column from Waters $(4.6 \mathrm{~mm} \times$ $250 \mathrm{~mm}$, Xbridge $\mathrm{C} 18,3 \mu \mathrm{m})$ was used for fractionation. The peptide mixture was loaded onto the column in buffer A2 $\left(\mathrm{H}_{2} \mathrm{O}, \mathrm{pH}=10\right)$. The elution gradient, $5-30 \%$ buffer $\mathrm{B} 2$ (90\% ACN; $\mathrm{pH}=10$; flow rate, $1 \mathrm{~mL} / \mathrm{min}$ ), was applied for 60 minutes. The eluted peptides were collected at 1 fraction per minute, and a total of 60 fractions were collected from 1 to 60 . The 60 fractions were then vacuum-dried, resuspended in $0.1 \%$ formic acid, and pooled into 20 samples by combining fractions 1, 21, and 41;2, 22, and 42; and so on.

\section{Liquid chromatography with tandem mass spectrometry}

Orbitrap Fusion Lumos Tribrid (Thermo Scientific) coupled with the EASY-nLC 1000 was used for analysis in the data-dependent acquisition-mass spectrometry (DDAMS) and DIA-MS modes. The digested peptides were separated on an RP C18 self-packing capillary LC column $(75 \mu \mathrm{m} \times 100 \mathrm{~mm}$; particle size $3 \mu \mathrm{m})$. The eluted gradient was $5-30 \%$ buffer B2 (0.1\% formic acid, $99.9 \%$ ACN; flow rate, $0.3 \mu \mathrm{L} / \mathrm{min}$ ), and peptides were eluted for 60 minutes.

To generate a spectral library, the 20 HPLC samples were analyzed in DDA mode. The parameters included the use of positive-mode and data-dependent MS/MS scans being performed per full scan with the top-speed mode $(3 \mathrm{~s})$. Precursor spectra $(350-1,500 \mathrm{~m} / \mathrm{z})$ were collected with a resolution of 60,000, and the automatic gain control (AGC) target was set to $1 \mathrm{e} 6$. Fragment spectra were collected at a resolution of 15,000 . The isolation width was set to $1.6 \mathrm{Da}$ with a collision energy of $32 \%$. Only precursors charged between +2 and +5 were acquired. Dynamic exclusion had a duration of $30 \mathrm{~s}$, and the maximum injection time was $50 \mathrm{~ms}$.

For DIA analysis, a variable isolation window with 38 windows was employed for MS acquisition. The specific window lists were constructed based on the DDA experiment of the pooled sample. According to the precursor $\mathrm{m} / \mathrm{z}$ distribution of the pooled sample, the precursor ion number was equalized in each isolation window. The full scan range was set from 400 to $900 \mathrm{~m} / \mathrm{z}$ and screened at a resolution of 120,000 , followed by DIA scans with a resolution of 30,000 (higher-energy C-trap dissociation [HCD] collision energy: 32\%; AGC target: 1e6; maximum injection time: $50 \mathrm{~ms}$ ).

\section{PRM analysis}

A Triple TOF 5600 mass spectrometer (AB Sciex, 
Framingham, MA, USA) was used for PRM analysis. An RP C18 self-packing capillary LC column $(75 \mu \mathrm{m} \times 100 \mathrm{~mm}$, $3 \mu \mathrm{m})$ was used to separate the peptides. The eluted gradient was $5-30 \%$ buffer B1 (0.1\% formic acid, $99.9 \%$ ACN; flow rate, $0.3 \mu \mathrm{L} / \mathrm{min}$ ), and peptides were eluted for 60 minutes. A spray voltage of $2.10 \mathrm{kV}$ and a capillary temperature of $60^{\circ} \mathrm{C}$ were used for ionization. The peptides (Table S2) were monitored by PRM acquisition mode to perform MS/MS scans of the precursor ions for all peptide markers along the complete chromatographic run, and each sample was run twice. The normalized collision energy was fixed to $35 \%$, and the accumulated time was $300 \mathrm{~s}$.

\section{Data processing}

The DDA data were then processed and analyzed by Proteome Discoverer (Thermo Scientific) software and searched against the human SwissProt database appended with the indexed retention time (iRT) fusion protein sequence (Biognosys, Zurich, Switzerland). The search was set as follows: up to 2 missed cleavage sites were included, carbamidomethyl cysteine was set as a fixed modification, and the precursor and fragment ion mass tolerances were $10 \mathrm{ppm}$ and $0.02 \mathrm{Da}$, respectively. The applied false discovery rate (FDR) for protein identification was less than $1.0 \%$. The results were imported to Spectronaut Pulsar (Biognosys) software to generate a spectral library.

The raw DIA data were analyzed by Spectronaut Pulsar (Biognosys) with default settings. In brief, the retention time prediction type was set to dynamic iRT. Interference correction on the MS2 level was enabled. Peptide intensity was calculated by summing the peak areas of their respective fragment ions for MS2, and the protein intensity was calculated by summing the intensity of their respective peptides. Cross-run normalization was enabled to correct for systematic variance in the LC-MS/MS performance, and a local normalization strategy was used. The normalization was based on the assumption that on average, a similar number of peptides was upregulated and downregulated, and the majority of the peptides within the sample were not regulated across runs or during the retention time (26). Protein inference was performed with the ID picker algorithm implemented in Spectronaut. All results were filtered by a $Q$ value cutoff of 0.01 (corresponding to an FDR of $1 \%$ ).

For the PRM mode, Skyline software (version 3.5.0.9319; https://skyline.ms/project/home/begin.view) was used for the selection of the suitable $\mathrm{m} / \mathrm{z}$ precursor ion to $\mathrm{m} / \mathrm{z}$ fragment ion transition for the selected candidate peptide biomarkers. Peptide settings were as follows: trypsin [KR/P] enzyme, up to 2 missed cleavage sites, a peptide length range from 8 to 25,2 variable modifications of carbamidomethyl on Cys and oxidation on Met, and a maximum number of variable modifications of 3 . Transition settings were as follows: the precursors were charged to 2 and 3; the ions were charged to 1 and 2; and the ion types were set as $b, y$, and $p$. The product ions were set to range from ion 3 to the last ion, and the ion match tolerance was set as $0.02 \mathrm{Da}$.

\section{Statistical analysis}

For DIA results, DEPs were defined as upregulated when abundance was $\geq 1.5$-fold increase, or as downregulated when abundance was $\leq 0.67$-fold reduced relative to earlystage group. For PRM results, the abundance change of peptides was inspected. In addition to a cutoff value of 1.5 -fold change relative to the early stage group, an adjusted $\mathrm{P}$ value (Bonferroni method) $<0.05$ was applied to define differential peptides.

\section{Bioinformatics analysis}

For the GO analysis, all of the DEPs were analyzed using R software (package: ClusterProfiler; The R Foundation for Statistical Computing; https://bioconductor.org/packages/ release/bioc/html/clusterProfiler.html).

For the IPA analysis, the SwissProt accession numbers were uploaded to IPA software (Ingenuity Systems, Mountain View, CA, USA). The proteins were mapped to the disease and functional categories, canonical pathways available in Ingenuity Knowledge Base, and other databases that were ranked by the $\mathrm{P}$ value.

\section{Results}

\section{Differential proteomic analysis}

In total, 31 patients were included in the experimental group, including 16 patients from the late stage and 15 patients from the early stage. The $31 \mathrm{AH}$ samples were analyzed using DIA methods, and overall, a total of 519 proteins (including 503 proteins with at least 2 unique peptides) were identified, with an average of 402 proteins being detected in each sample (available online: https:// cdn.amegroups.cn/static/public/atm-2 1-457-1.xlsx). 
A

Late stage - early stage (PCA-X)

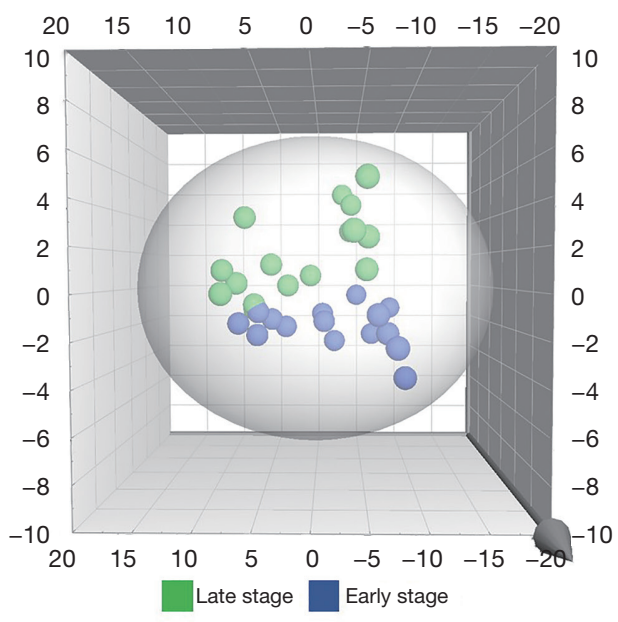

B

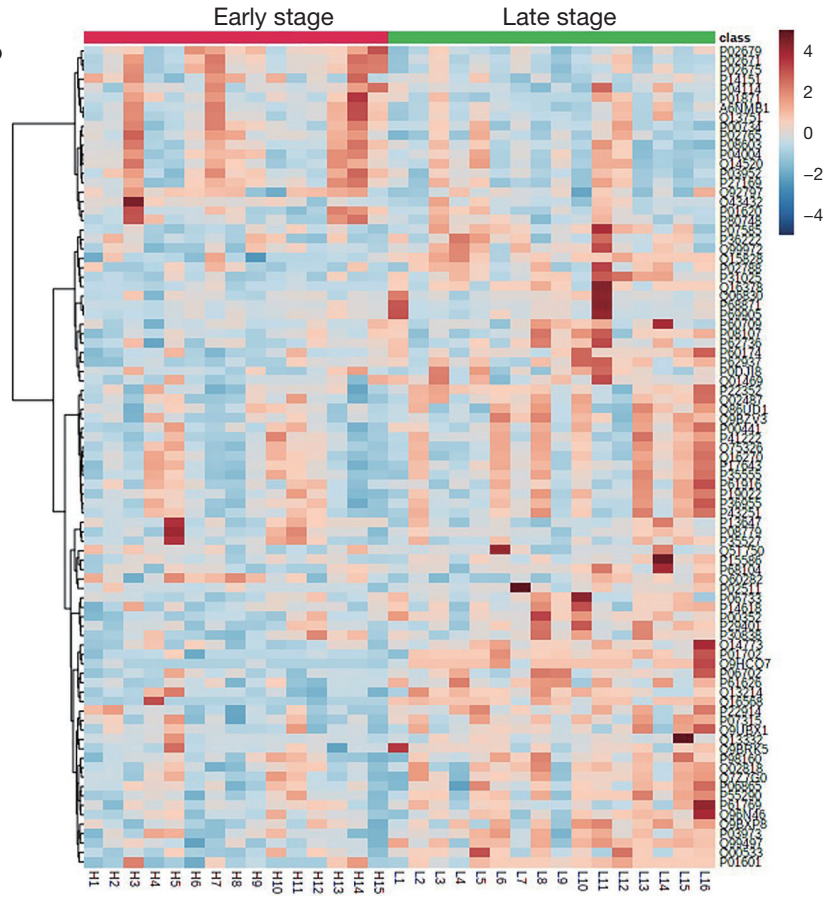

Figure 2 AH proteome profile analysis. (A) 3D plot of the PCA result. The ellipse represents a 95\% confidence interval using Hotelling's T2 statistic. Observations situated far outside the ellipse are outliers. (B) Heatmap of 87 DEPs between the 2 groups. AH, aqueous humor; PCA, principal component analysis. DEPs, differentially expressed proteins.

The technical variation in the analysis was evaluated by calculating the coefficient of variation $(\mathrm{CV})$ of the protein abundance among $4 \mathrm{QC}$ replicates $\left(\mathrm{R}^{2}=0.864\right)$. As a result, 393 proteins with $\mathrm{CV}<0.6$ were used to identify the DEPs (Figure S1).

To show the difference between the 2 groups, principal component analysis (PCA) was used. The 3D plot showed that the 2 groups had clear distinctions in their proteomics profiles (Figure 2A).

To identify the DEPs, the cutoff value of a 1.5 -fold change (late stage/early stage) between the 2 groups was used. A total of 87 proteins were found, among which 23 were downregulated and 64 were upregulated. A heatmap based on the DEPs showed that the 2 groups expressed different proteomic patterns (Figure 2B).

\section{Biological function analysis of the DEPs}

To further investigate the biological function of the different proteins, 87 DEPs were subjected to GO annotations and IPA analysis.

The GO annotations for biological process (BP), CC, and molecular function $(\mathrm{MF})$ were determined (ClusterProfiler,
R software; Figure $3 A-3 C$ ). In the BP category, GO terms relating to immunology, hemodynamics, and apoptosis were mostly enriched. In the CC category, collagen-containing extracellular matrix $(\mathrm{ECM} ; \mathrm{P}=3.54 \mathrm{E}-18$, ratio $=0.29)$ showed the highest percentage. Regarding the MF category, cell adhesion was overrepresented. The upregulated cell adhesion proteins in this study were related to cell-ECM adhesions, including fibrillin-1, vitronectin, and cadherin. According to a previous study, the RGC loss in glaucoma is associated with the ECM in the optic nerve head prelaminar region (27). In the prelaminar region of the optic nerve head, the connective tissue sheaths around the capillaries are thickened, which can influence the oxygen and nutrition transport, and finally contribute to RGC loss (28).

The IPA analysis revealed further detailed functional changes of the DEPs (Figure 4A, available online: https:// cdn.amegroups.cn/static/public/atm-21-457-2.xls). In accordance with the GO annotations for BP, many of the proteins were relevant to vascular disease, cell death and survival, and the inflammatory response. Additionally, a few proteins were involved in neurological disease, which suggests that neurodegenerative processes occurred during the progression of symptoms (29). Notably, quantity of $\mathrm{Ca}^{2+}$ 

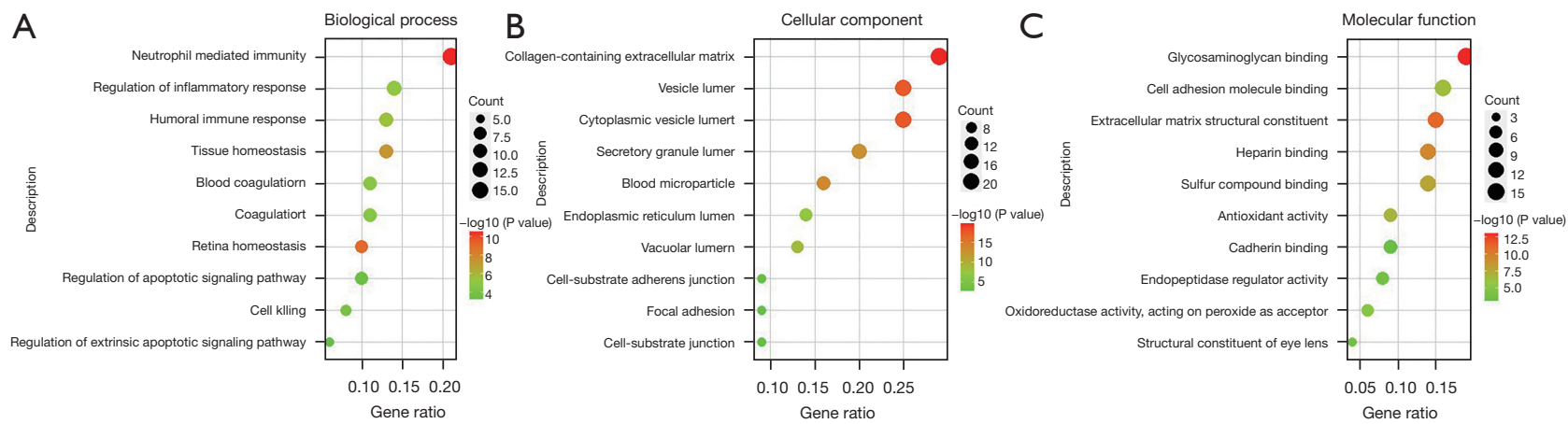

Figure 3 The GO annotations of DEPs. (A) Biological Process. (B) Cellular Component. (C) Molecular Function. GO, Gene Ontology; DEPs, differentially expressed proteins.

A

Diseases or functions annotation

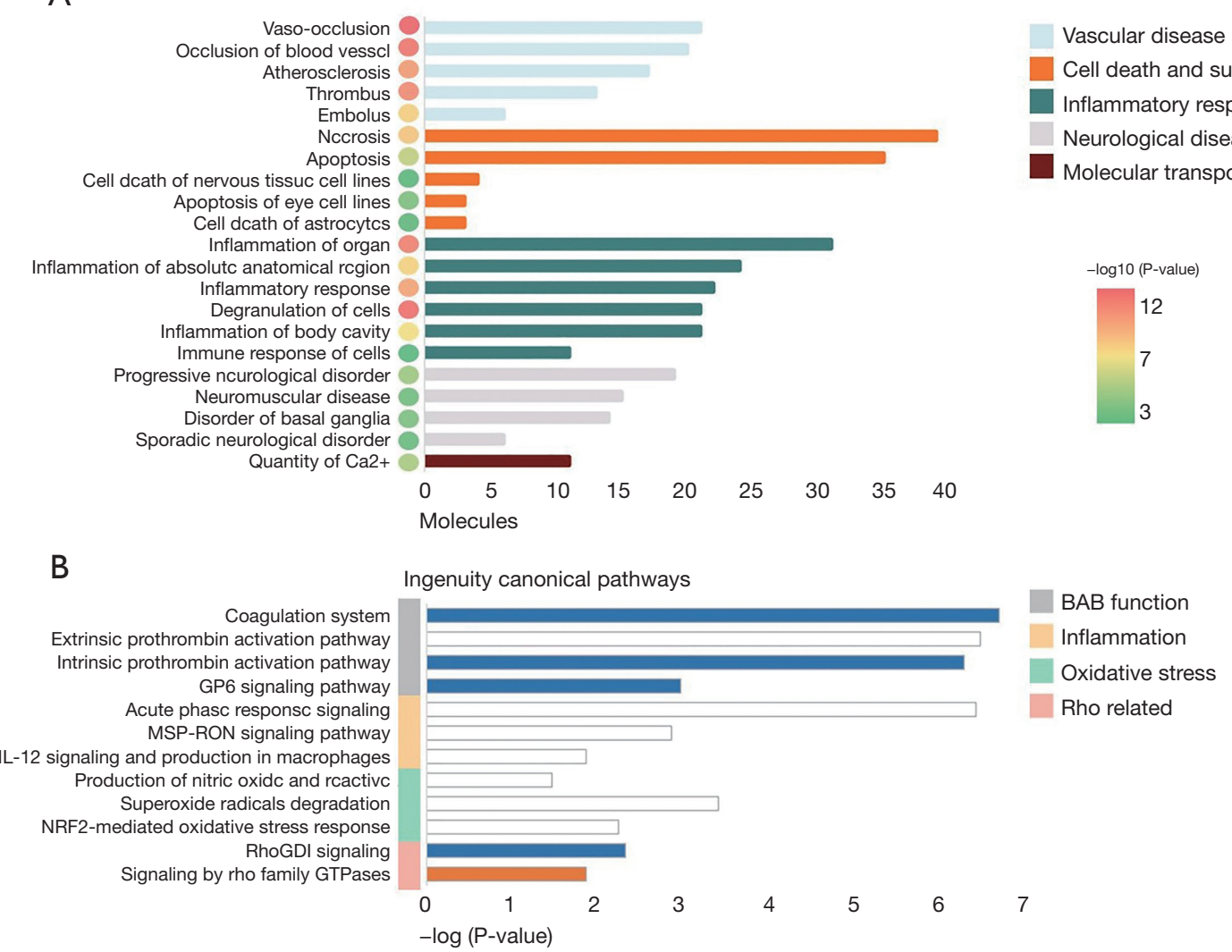

Figure 4 IPA analysis of DEPs. (A) The diseases or functions annotation. The color of the dot indicates the level of significance. (B) The major canonical pathways of DEPs. The orange bar represents significantly activated, the blue bar represents significantly inhibited, and the white bar represents no significant change. BAB, blood-aqueous humor barrier; IPA, ingenuity pathway analysis; DEPs, differentially expressed proteins. 
Table 2 Validated proteins by parallel reaction monitoring

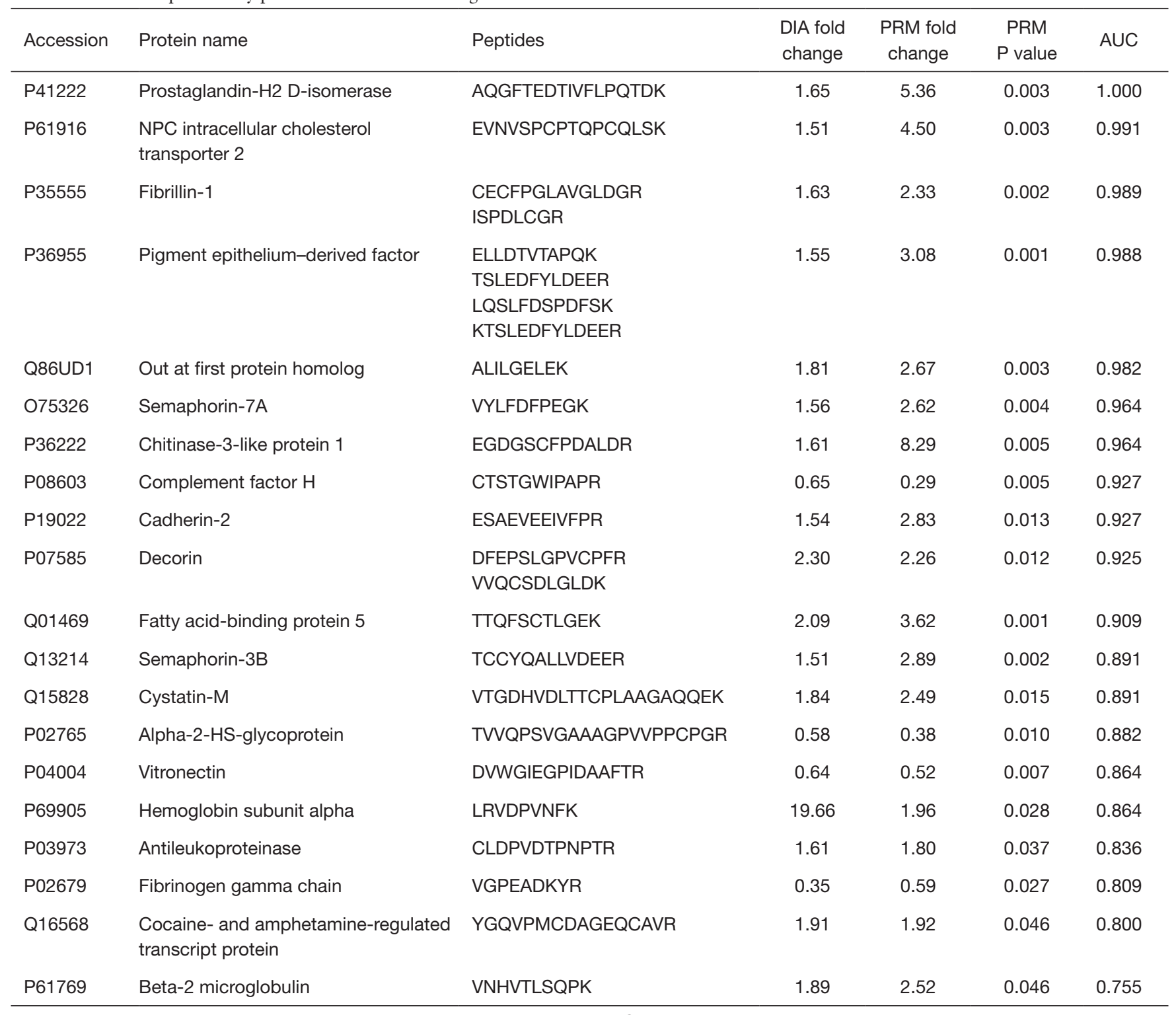

DIA, data-independent acquisition; PRM, parallel reaction monitoring; AUC, area under curve.

function was annotated, which was associated with the death of inner retinal cells in a previous report (30).

The IPA analysis of canonical pathways indicated those pathways in which the DEPs were enriched (Figure $4 B$, available online: https://cdn.amegroups.cn/static/public/ atm-21-457-2.xls). Pathways related to blood-aqueous barrier (BAB) function, inflammation, and oxidative stress were found, and Rho-related pathways were also observed.

\section{PRM validation}

To validate the results of the discovery phase, 21 samples were recruited, including 11 samples from the early-stage group and 10 from the late-stage group. Technical variation in the PRM analysis was evaluated by calculating the $\mathrm{CV}$ of the peptide abundance among 3 QC replicates $\left(\mathrm{R}^{2}=0.975\right)$, and the distribution of the CVs is shown in Figure S2. A 

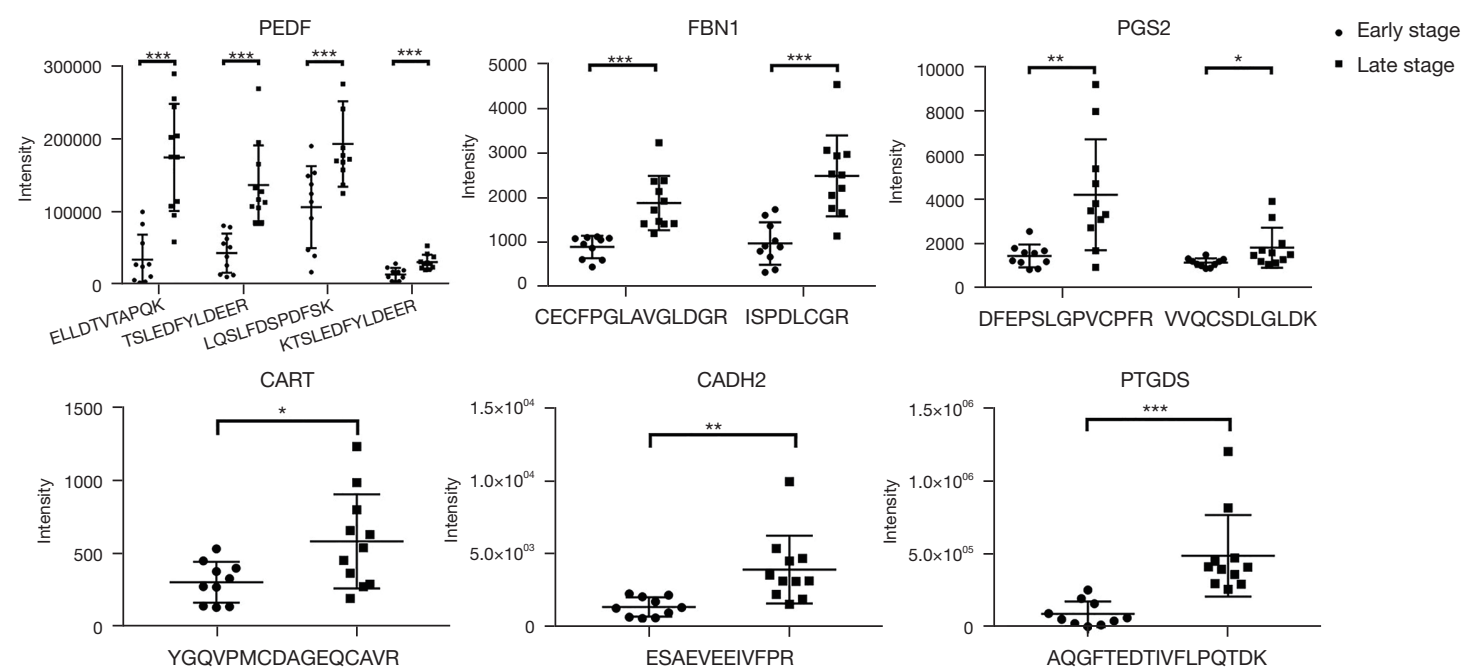

Figure 5 The validated proteins by PRM method. Peptides form the same protein are shown in a plot. Detailed information is shown in Table S2. The asterisks indicate the level of significance. * $\mathrm{P}<0.05$; ** $\mathrm{P}<0.01$; *** $\mathrm{P}<0.001$. PRM, parallel reaction monitoring; $\mathrm{PEDF}$, pigment epithelium-derived factor; FBN1, fibrillin-1; CART, cocaine- and amphetamine-regulated transcript; CDH2, cadherin-2; PTGDS, prostaglandin-H2 D-isomerase.

total of 20 proteins (16 upregulated and 4 downregulated) showed consistent results with the experimental group results (Table 2, Table S2). The abundance change of peptides was inspected (Figure S3). Among them, 4 peptides from PEDF, 2 peptides from FBN1, and 2 peptides from PGS2 were validated. The peptides of several key proteins (CART, CDH2, and PTGDS) were also validated, and peptides from the same protein showed a similar trend (Figure 5).

The performance of these proteins in distinguishing early-stage VF loss from late-stage VF loss was evaluated by receiver operating characteristic (ROC) analysis, and the results ranged from 0.755 to 1.000 (Table 2). Among them, prostaglandin-H2 D-isomerase (PTGDS) could achieve the best results $(\mathrm{ROC}=1)$ and might be clinically useful as an optic nerve damage biomarker.

\section{Discussion}

As previous studies have reported, the $\mathrm{AH}$ proteome correlates with the mechanisms of many eye disorders (31-33). In this study, we used the AH proteome to evaluate the characteristics of VF loss in the AACG cohort. A total of 87 DEPs were found. The DEPs functional analysis helped further clarify the pathological changes involved. In general, AACG-related processes were annotated in our study, especially those induced by ischemia, such as ocular hemodynamic and vascular changes, immune response, and apoptosis.

Regarding ocular hemodynamics, increased IOP can lead to hemodynamic changes in the ocular blood vessels that supply the optic nerve (7). Alterations may cause ischemic death of RGCs by reducing the supply of oxygen and nutrients (34,35). Additionally, blocked vessels and abnormal vascular walls result in dysfunction of the eye vessels, which may lead to poor perfusion in the eyes and ischemic injury (3). This study found many of the DEPs were involved in vascular pathological changes, such as vaso-occlusion and thrombus. These phenomena tended to cause ischemia in the eyes and then lead to injuries to the local tissue. Moreover, ischemia- and hypoxia-induced pathological ocular angiogenesis may lead to significant visual impairment (36). A previous study observed the development of tortuous and dilated retinal vessels throughout the whole retina in an ocular hypertension mouse model (5). These findings indicated the AACG might be related to ocular neovascularization (5). The role of ocular angiogenesis should be borne in mind when investigating the progression of optic neuropathy. Once angiogenesis occurs, the function of pigment epitheliumderived factor (PEDF) has to be determined, which has potent antiangiogenic actions and protective effects against retinal cell death (37). It was reported that PEDF overexpression ameliorated ischemia-induced retinal 
neovascularization contributed to a protective effect on the blood-retinal barrier and attenuated pathological neovascularization under pathogenic conditions (37). In this study, we observed that the expression of PEDF was significantly different between the 2 groups. The upregulation of PEDF in the late-stage group might have promoted the regression of neovascularization by suppressing the angiogenic effects of hypoxia inducible factor-1 (HIF-1), decreasing vascular endothelial growth factor (VEGF) levels, and downregulating matrix metalloproteinases (MMP)-2 and -9 expression and activities (36).

Another protein-regulating vascular function that was identified in our study was cocaine- and amphetamineregulated transcript (CART). A previous study revealed the mechanism by which CART regulates vascular tone (38): CART stimulates the de novo synthesis of bioactive endothelin and newly synthesized endothelin and then activates smooth muscle-bound ETA receptors, evoking dramatic vasoconstriction (38). A previous study reported that CART increased neuronal cell death in culture and was associated with higher mortality after experimental stroke in vivo (39). In the same study, researchers proposed that the vasoconstriction effect of CART is amplified in the ischemia-compromised cerebral circulation, exacerbating injury and hindering recovery from stroke (39). The results observed in this study showed an upregulation of CART in the late-stage group and that a high level of CART might constrict the blood vessels as mentioned above, reducing the blood flow, and then causing ischemic injury.

In glaucoma, inflammatory responses have been identified as common features, both in clinical and in experimental settings (29). Under normal conditions, AH exhibits anti-inflammatory potential, which inhibits neutrophil activation, suppresses NO production by macrophages, and interferes with complement activation (40). In this study, many DEP functions were related to inflammatory response, such as neutrophil-mediated immunity and NO production by macrophages, which may result in the death of RGCs and the loss of sight (41). A previous study pointed out that ischemic events could produce a large number of chemokines that attract leukocytes (42). A mass of leukocytes blocks blood vessels and breaks the blood-retina barrier (BRB), causing failed filtration of the leukocytes (42). Other studies reported that Rho GTPase/Rho kinase signaling contributes to leukocyte extravasation (43-45). In our study, this pathway was predicted as being more active in the late-stage group, indicating that leukocyte extravasation was more facilitative in the late-stage group. As a result, these immune cells would be distributed ubiquitously in the ischemic region and produce an abundance of reactive oxygen species (ROS) while performing their functions (46). It has been reported that ROS are cytotoxic to RGCs and to lead to necrotic cell death by direct oxidative damage to cellular constituents and apoptotic death (47-50). In this study, we found the NRF2 pathway in our pathway analysis and superoxide radical degradation-related proteins (SOD1 and TYRP1) were upregulated in the late-stage group, which may be a response to excessive ROS. Our results and previous studies $(41,46)$ indicated that ocular ischemia might activate inflammation pathways and produce massive amounts of ROS, finally causing damage to RGCs.

The functional annotation by IPA showed that many DEPs were related to the process of cell death, including the death of nervous tissue cell lines, the death of astrocytes, and the apoptosis of eye cell lines. Apoptosis is the main pathogenesis after retinal ischemia-reperfusion (RIR) and causes injury to RGCs (51). A previous study found that excess $\mathrm{Ca}^{2+}$ and $\mathrm{ROS}$ can cause the activation of $\mathrm{BH} 3$-only proteins and then activate Bax, resulting in apoptosis (52). The IPA function analysis results showed quantity of $\mathrm{Ca}^{2+}$, superoxide radicals degradation, and the death receptor signaling pathway were upregulated in the late group. Another apoptosis-related pathway, BEX2 was also found in the IPA analysis, and a previous study reported that BEX2 pathway downregulation promoted cell apoptosis (53); therefore, it might be a protective mechanism in glaucoma. In the BEX2 pathway, cadherin-2 (CDH2) has been previously demonstrated to decrease the apoptosis of mouse endothelial cells in culture (54). In this study, CDH2 was upregulated in the late-stage group, and thus might have a protective effect on RGCs and reduce apoptosis.

Taken together, we integrated the results of functional analysis and attempted to infer the connection between them. Other studies have reported that elevated IOP during AACG altered the function of blood vessels in the eye, causing ischemia, while other activities, such as neovascularization and vasoconstriction, also contributed to ischemia $(3,7,34,35)$. Focal ischemia might induce an inflammatory response, and then immune cells might produce harmful ROS. Eventually, excessive ROS results in apoptosis by activating the apoptotic pathway and causing oxidative damage to the cells (Figure 6).

We also sought to use $\mathrm{AH}$ protein biomarkers to provide an objective evaluation of VF loss. Among the 20 


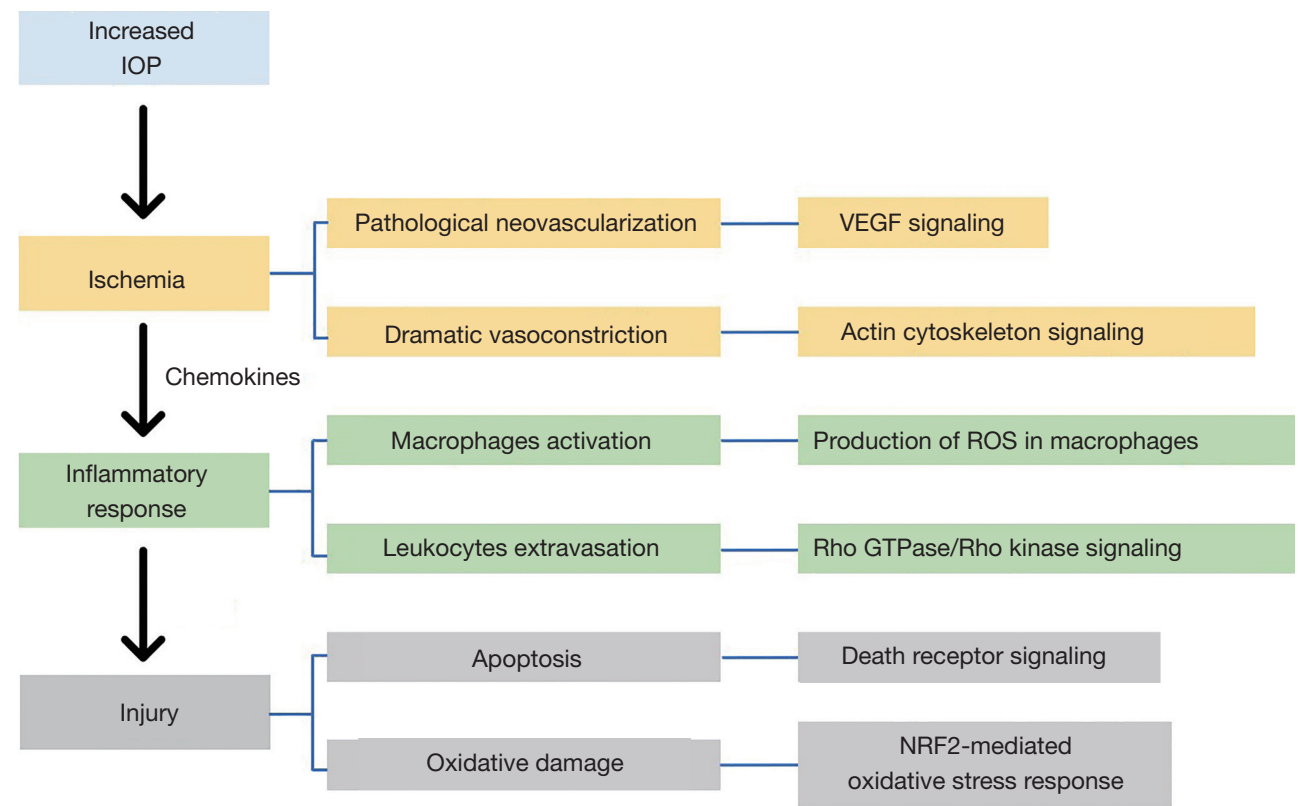

Figure 6 The potential mechanism of VF loss in AACG. The major functions and pathways are shown. VF, visual field; AACG, acute angleclosure glaucoma; IOP, intraocular pressure.

validated proteins, PTGDS showed the best results, with $100 \%$ sensitivity and specificity. A previous study reported that it could catalyze the conversion of PGH2 to PGD2. Previously, PGD2 was found to maintain normal cerebral blood flow and contribute to recovery from hypoxia from hypoxic-ischemic injury in the mouse brain (55), and it was also found to modulate immune and inflammatory responses and induce apoptosis and neuroprotection (56). Another study found that PTGDS protects against oxidative stressmediated neurodegenerative diseases (57). In this study, the IPA functional analysis indicated that ocular hemodynamic changes and oxidative damage-related pathways, such as occlusion in blood vessels, vasoconstriction, and production of $\mathrm{NO}$ and ROS, were upregulated. Therefore, the upregulation of PTGDS in the late stage might play a protective role during AACG to improve ocular blood perfusion and promote ROS scavenging. Therefore, it has potential for use as an objective biomarker of VF loss, but this needs to be confirmed by large-scale clonal validation.

\section{Conclusions}

In this study, we used a proteomic method to investigate the process of VF loss during AACG. Our study reported the proteomic difference between 2 stages of pathogenesis. Functional analysis showed that the inflammatory response, ocular hemodynamics, and cell apoptosis were closely related to the observed pathological changes. Although the cross-talk between AH proteins and optic nerve behavior is still unclear, our findings may be helpful in further proteomic research of VF loss in AACG. The results of our study indicated that AH could reflect changes in different stages of VF loss and that PTGDS has potential as an objective biomarker of VF loss.

For future work, the following issues should be addressed. First, the samples in this study were from a single center, and thus a large-scale analysis including different glaucoma and control groups (cataracts) from multiple centers should be used to validate the conclusions. Second, the present study did not evaluate the impact factors of $\mathrm{AH}$ proteome; therefore, related factors, including age, gender, $\mathrm{BAB}$, and others should be comprehensively analyzed. Third, for examining the role of proteins in $\mathrm{VF}$ loss, molecular biology and related animal models should be used, which may help clarify the possible mechanism of VF loss and improve our understanding of it.

\section{Acknowledgments}

Funding: This work was supported by National Key Research and Development Program of China (No. 2016YFC1306300 and 2018YFC0910202), the National 
Natural Science Foundation of China (No. 30970650, $31200614,31400669,81371515,81170665$, and 81560121), the National Natural Science Foundation of China Youth Science Foundation Project (No. 81700857), the Beijing Natural Science Foundation (No. 7172076), Beijing Medical Research (No. 2018-7), the Beijing Cooperative Construction Project (No. 110651103), Beijing Normal University (No. 11100704), Peking Union Medical College Hospital (No. 2016-2.27), the CAMS Innovation Fund for Medical Sciences (No. 2017-I2M-1-009 and 2018I2M-1-001), the Jilin Science and Technology Office (No. 20190201051JC), and the Biologic Medicine Information Center of China, National Scientific Data Sharing Platform for Population and Health.

\section{Footnote}

Reporting Checklist: The authors have completed the MDAR reporting checklist. Available at https://dx.doi. org/10.21037/atm-21-457

Data Sharing Statement: Available at https://dx.doi. org/10.21037/atm-21-457

Peer Review File: Available at https://dx.doi.org/10.21037/ atm-21-457

Conflicts of Interest: All authors have completed the ICMJE uniform disclosure form (available at https://dx.doi. org/10.21037/atm-21-457). XL was employed by Shanghai AB Sciex Analytical Instrument Trading Co., Ltd. The other authors have no conflicts of interest to declare.

Ethical Statement: The authors are accountable for all aspects of the work in ensuring that questions related to the accuracy or integrity of any part of the work are appropriately investigated and resolved. All volunteers were given a verbal explanation of the study before enrolment, and each participant signed an informed consent form. The consent procedure and the research protocol for this study were approved by the Ethics Committee for Human and Animal Research in Peking Union Medical College (047-2019). The study methodologies conformed to the Declaration of Helsinki (as revised in 2013).

Open Access Statement: This is an Open Access article distributed in accordance with the Creative Commons Attribution-NonCommercial-NoDerivs 4.0 International
License (CC BY-NC-ND 4.0), which permits the noncommercial replication and distribution of the article with the strict proviso that no changes or edits are made and the original work is properly cited (including links to both the formal publication through the relevant DOI and the license). See: https://creativecommons.org/licenses/by-nc-nd/4.0/.

\section{References}

1. Andreatta W, Elaroud I, Nightingale P, et al. Long-term outcomes after acute primary angle closure in a White Caucasian population. BMC Ophthalmol 2015;15:108.

2. Pohl H, Tarnutzer AA. Acute Angle-Closure Glaucoma. N Engl J Med 2018;378:e14.

3. Xie M, Fan N, Tian X, et al. Optic nerve damage and its mechanism in acute angle-closure glaucoma. International Review of Ophthalmology 2015;39:247-52.

4. Flores-Sánchez BC, Tatham AJ. Acute angle closure glaucoma. Br J Hosp Med (Lond) 2019;80:C174-9.

5. Mukai R, Park DH, Okunuki Y, et al. Mouse model of ocular hypertension with retinal ganglion cell degeneration. PLoS One 2019;14:e0208713.

6. Quigley HA. Glaucoma. Lancet 2011;377:1367-77.

7. Marjanović I, Martinez A, Marjanović M, et al. Changes in the retrobulbar arterial circulation after decrease of the elevated intraocular pressure in men and women with primary open angle glaucoma. Srp Arh Celok Lek 2013;141:728-31.

8. Fick CM, Dubielzig RR. Short posterior ciliary artery anatomy in normal and acutely glaucomatous dogs. Vet Ophthalmol 2016;19:43-9.

9. Lu DW, Chen YH, Chang CJ, et al. Nitric oxide levels in the aqueous humor vary in different ocular hypertension experimental models. Kaohsiung J Med Sci 2014;30:593-8.

10. Sucher NJ, Lipton SA, Dreyer EB. Molecular basis of glutamate toxicity in retinal ganglion cells. Vision Res 1997;37:3483-93.

11. Lusardi TA, Wolf JA, Putt ME, et al. Effect of acute calcium influx after mechanical stretch injury in vitro on the viability of hippocampal neurons. J Neurotrauma 2004;21:61-72.

12. Morrison JC, Johnson EC, Cepurna W, et al. Understanding mechanisms of pressure-induced optic nerve damage. Prog Retin Eye Res 2005;24:217-40.

13. Grus FH, Joachim SC, Pfeiffer N. Proteomics in ocular fluids. Proteomics Clin Appl 2007;1:876-88.

14. Funke S, Perumal N, Bell K, et al. The potential impact of recent insights into proteomic changes associated with 
glaucoma. Expert Rev Proteomics 2017;14:311-34.

15. Youngblood H, Robinson R, Sharma A, et al. Proteomic Biomarkers of Retinal Inflammation in Diabetic Retinopathy. Int J Mol Sci 2019;20:4755.

16. Kliuchnikova AA, Samokhina NI, Ilina IY, et al. Human aqueous humor proteome in cataract, glaucoma, and pseudoexfoliation syndrome. Proteomics 2016;16:1938-46.

17. Klenkler B, Sheardown H. Growth factors in the anterior segment: role in tissue maintenance, wound healing and ocular pathology. Exp Eye Res 2004;79:677-88.

18. Vesaluoma M, Mertaniemi P, Mannonen S, et al. Cellular and plasma fibronectin in the aqueous humour of primary open-angle glaucoma, exfoliative glaucoma and cataract patients. Eye (Lond) 1998;12 ( Pt 5):886-90.

19. Schlötzer-Schrehardt U, Lommatzsch J, Küchle M, et al. Matrix metalloproteinases and their inhibitors in aqueous humor of patients with pseudoexfoliation syndrome/ glaucoma and primary open-angle glaucoma. Invest Ophthalmol Vis Sci 2003;44:1117-25.

20. Aggarwala KRG. Ocular Accommodation, Intraocular Pressure, Development of Myopia and Glaucoma: Role of Ciliary Muscle, Choroid and Metabolism. Med Hypothesis Discov Innov Ophthalmol 2020;9:66-70.

21. Croft MA, Lütjen-Drecoll E, Kaufman PL. Agerelated posterior ciliary muscle restriction - A link between trabecular meshwork and optic nerve head pathophysiology. Exp Eye Res 2017;158:187-9.

22. Izzotti A, Longobardi M, Cartiglia C, et al. Proteome alterations in primary open angle glaucoma aqueous humor. J Proteome Res 2010;9:4831-8.

23. Kaeslin MA, Killer HE, Fuhrer CA, et al. Changes to the Aqueous Humor Proteome during Glaucoma. PLoS One 2016;11:e0165314.

24. Wang LM, Dong LJ, Liu X, et al. Proteomic analysis of aqueous humor in acute primary angle-closure glaucoma. Zhonghua Yan Ke Za Zhi 2019;55:687-94.

25. Hirasawa K, Shoji N, Morita T, et al. A modified glaucoma staging system based on visual field index. Graefes Arch Clin Exp Ophthalmol 2013;251:2747-52.

26. Yu M, Xie F, Liu X, et al. Proteomic Study of Aqueous Humor and Its Application in the Treatment of Neovascular Glaucoma. Front Mol Biosci 2020;7:587677.

27. Schneider M, Fuchshofer R. The role of astrocytes in optic nerve head fibrosis in glaucoma. Exp Eye Res 2016;142:49-55.

28. Tektas OY, Lütjen-Drecoll E, Scholz M. Qualitative and quantitative morphologic changes in the vasculature and extracellular matrix of the prelaminar optic nerve head in eyes with POAG. Invest Ophthalmol Vis Sci 2010;51:5083-91.

29. Russo R, Varano GP, Adornetto A, et al. Retinal ganglion cell death in glaucoma: Exploring the role of neuroinflammation. Eur J Pharmacol 2016;787:134-42.

30. Oka T, Tamada Y, Nakajima E, et al. Presence of calpaininduced proteolysis in retinal degeneration and dysfunction in a rat model of acute ocular hypertension. J Neurosci Res 2006;83:1342-51.

31. Määttä M, Tervahartiala T, Harju M, et al. Matrix metalloproteinases and their tissue inhibitors in aqueous humor of patients with primary open-angle glaucoma, exfoliation syndrome, and exfoliation glaucoma. J Glaucoma 2005;14:64-9.

32. Ozcan AA, Ozdemir N, Canataroglu A. The aqueous levels of TGF-beta2 in patients with glaucoma. Int Ophthalmol 2004;25:19-22.

33. Funding M, Vorum H, Honoré B, et al. Proteomic analysis of aqueous humour from patients with acute corneal rejection. Acta Ophthalmol Scand 2005;83:31-9.

34. Caprioli J, Coleman AL; Blood Flow in Glaucoma Discussion. Blood pressure, perfusion pressure, and glaucoma. Am J Ophthalmol 2010;149:704-12.

35. Harris A, Guidoboni G, Arciero JC, et al. Ocular hemodynamics and glaucoma: the role of mathematical modeling. Eur J Ophthalmol 2013;23:139-46.

36. Cabral T, Mello LGM, Lima LH, et al. Retinal and choroidal angiogenesis: a review of new targets. Int J Retina Vitreous 2017;3:31.

37. Park K, Jin J, Hu Y, et al. Overexpression of pigment epithelium-derived factor inhibits retinal inflammation and neovascularization. Am J Pathol 2011;178:688-98.

38. Iliff JJ, Alkayed NJ, Gloshani KJ, et al. Cocaine- and amphetamine-regulated transcript (CART) peptide: a vasoactive role in the cerebral circulation. J Cereb Blood Flow Metab 2005;25:1376-85.

39. Xu Y, Zhang W, Klaus J, et al. Role of cocaineand amphetamine-regulated transcript in estradiolmediated neuroprotection. Proc Natl Acad Sci U S A 2006;103:14489-94.

40. Mac Nair CE, Nickells RW. Neuroinflammation in Glaucoma and Optic Nerve Damage. Prog Mol Biol Transl Sci 2015;134:343-63.

41. Neufeld AH, Kawai Si, Das S, et al. Loss of retinal ganglion cells following retinal ischemia: the role of inducible nitric oxide synthase. Exp Eye Res 2002;75:521-8.

42. Guo M, Yan H. Research progress in the mechanism and treatment of retinal ischemia reperfusion injury. Chinese 
Journal of Ocular Fundus Diseases 2020;36:483-8.

43. Hirooka K, Miyamoto O, Jinming P, et al. Neuroprotective effects of $\mathrm{D}$-allose against retinal ischemia-reperfusion injury. Invest Ophthalmol Vis Sci 2006;47:1653-7.

44. Millán J, Ridley AJ. Rho GTPases and leucocyte-induced endothelial remodelling. Biochem J 2005;385:329-37.

45. Wittchen ES, van Buul JD, Burridge K, et al. Trading spaces: Rap, Rac, and Rho as architects of transendothelial migration. Curr Opin Hematol 2005;12:14-21.

46. Zhu YJ, Jin M. Advances in the mechanism of retina ischemia-reperfusion injury. Chinese Journal of Pathophysiology 2007;23:195-200.

47. Kaur C, Foulds WS, Ling EA. Hypoxia-ischemia and retinal ganglion cell damage. Clin Ophthalmol 2008;2:879-89.

48. Kortuem K, Geiger LK, Levin LA. Differential susceptibility of retinal ganglion cells to reactive oxygen species. Invest Ophthalmol Vis Sci 2000;41:3176-82.

49. Levkovitch-Verbin H, Harris-Cerruti C, Groner Y, et al. RGC death in mice after optic nerve crush injury: oxidative stress and neuroprotection. Invest Ophthalmol Vis Sci 2000;41:4169-74.

50. Lieven CJ, Vrabec JP, Levin LA. The effects of oxidative stress on mitochondrial transmembrane potential in retinal ganglion cells. Antioxid Redox Signal 2003;5:641-6.

Cite this article as: $\mathrm{Xu} \mathrm{J}$, Zhao L, Liu X, Sun H, Liu X, Guo Z, Wang Y, Sun W. Aqueous humor proteomic analysis of acute angle-closure glaucoma with visual field loss. Ann Transl Med 2021;9(21):1611. doi: 10.21037/atm-21-457
51. He Y, Liu JN, Zhang JJ, et al. Involvement of microRNA181a and Bim in a rat model of retinal ischemiareperfusion injury. Int J Ophthalmol 2016;9:33-40.

52. Chen L, Shi JM. Research advances on mechanism of apoptosis in retinal ganglion cells in glaucoma. Recent Advances in Ophthalmology 2013;33:384-8.

53. Zhou X, Meng Q, Xu X, et al. Bex2 regulates cell proliferation and apoptosis in malignant glioma cells via the c-Jun NH2-terminal kinase pathway. Biochem Biophys Res Commun 2012;427:574-80.

54. Giampietro C, Taddei A, Corada M, et al. Overlapping and divergent signaling pathways of $\mathrm{N}$-cadherin and $\mathrm{VE}$ cadherin in endothelial cells. Blood 2012;119:2159-70.

55. Taniguchi H, Mohri I, Okabe-Arahori H, et al. Prostaglandin D2 protects neonatal mouse brain from hypoxic ischemic injury. J Neurosci 2007;27:4303-12.

56. Wei Q, Zhang T, Fan J, et al. Pathological myopia-induced antioxidative proteins in the vitreous humor. Ann Transl Med 2020;8:193.

57. Fukuhara A, Yamada M, Fujimori K, et al. Lipocalin-type prostaglandin D synthase protects against oxidative stressinduced neuronal cell death. Biochem J 2012;443:75-84.

(English Language Editors: J. Jones and J. Gray) 


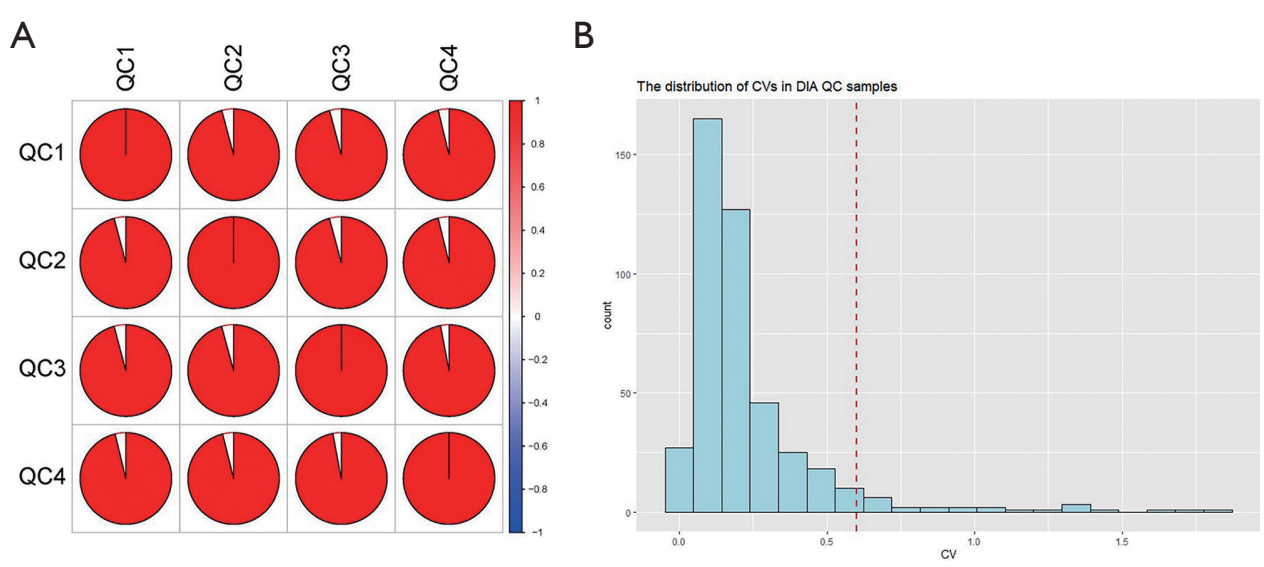

Figure S1 Correlation and CVs of QC samples in DIA. (A) Correlation analysis results. (B) CV distribution. CV, coefficient of variation; QC, quality control; DIA, data-independent acquisition.

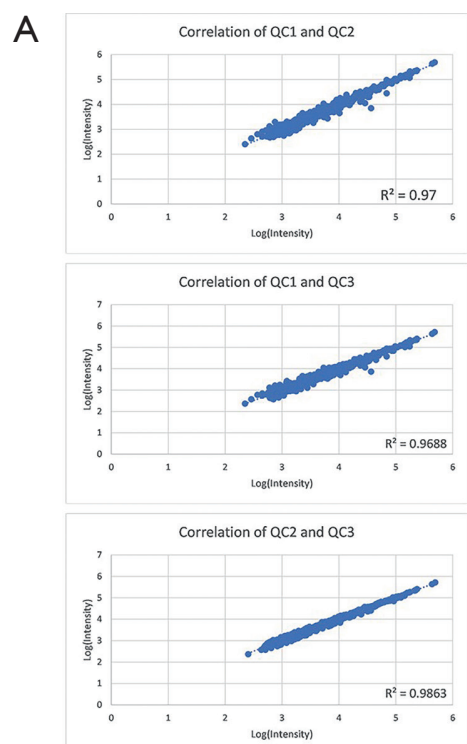

B

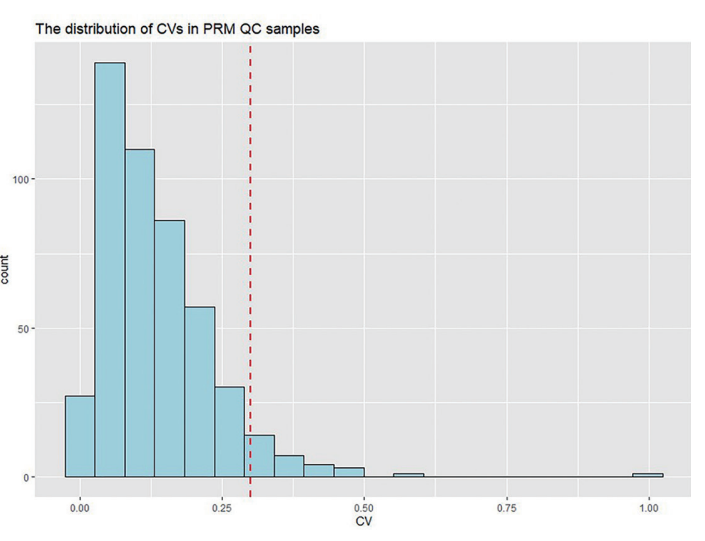

Figure S2 Correlation and CVs of QC samples in PRM. (A) Correlation analysis results. (B) CV distribution. CV, coefficient of variation; QC, quality control; PRM, parallel reaction monitoring.
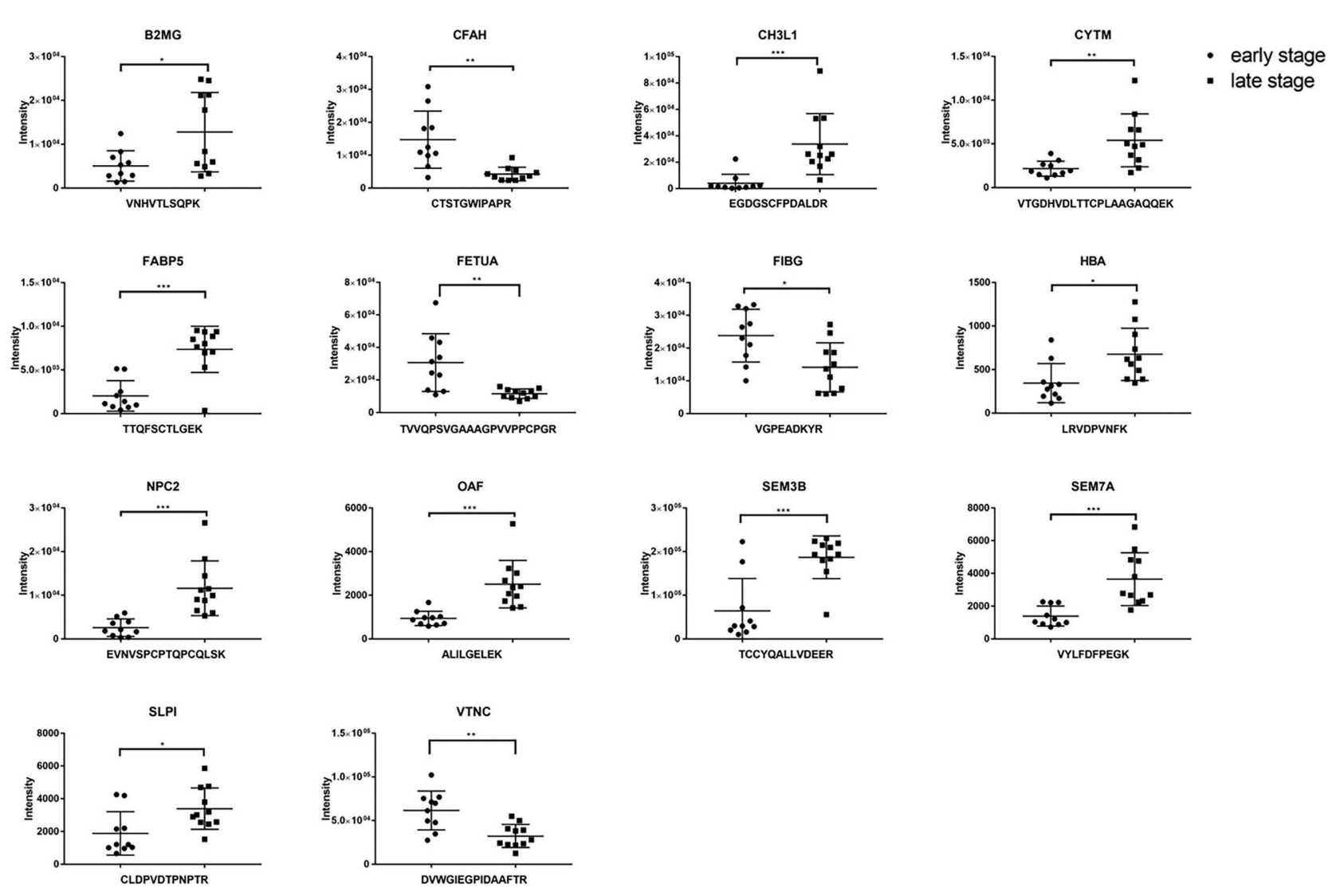
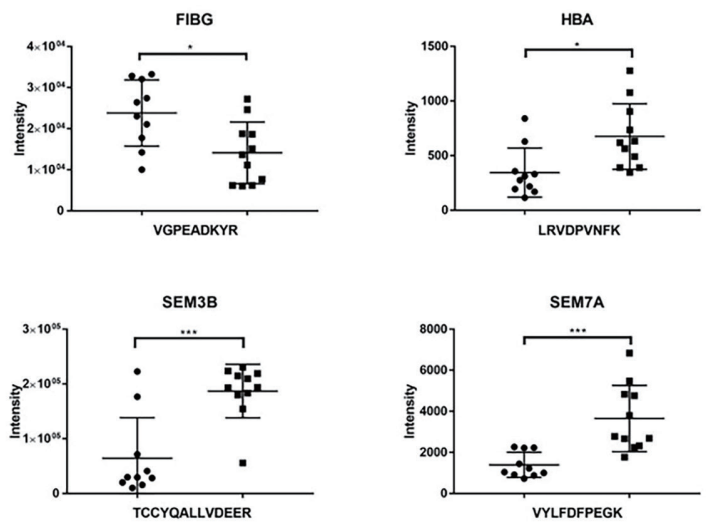

Figure S3 The validated proteins by PRM method. The asterisks indicate the level of significance. *, $\mathrm{P}<0.05$; ** $\mathrm{P}<0.01$; ***, $\mathrm{P}<0.001$. PRM, parallel reaction monitoring. 


\begin{tabular}{|c|c|c|c|c|c|c|}
\hline Number & Gender & Age & Diagnosis & VFI & IOP & Group \\
\hline $\mathrm{H} 1$ & Female & 70 & AACG & 92 & 8 & Experiment \\
\hline H2 & Female & 67 & AACG & 94 & 25 & Experiment \\
\hline H3 & Female & 59 & AACG & 95 & 10 & Experiment \\
\hline $\mathrm{H} 4$ & Female & 64 & AACG & 97 & 17 & Experiment \\
\hline H5 & Female & 64 & AACG & 85 & 16 & Experiment \\
\hline $\mathrm{H} 6$ & Female & 73 & AACG & 98 & 13 & Experiment \\
\hline $\mathrm{H} 7$ & Female & 68 & AACG & 95 & 42 & Experiment \\
\hline $\mathrm{H} 8$ & Female & 64 & AACG & 97 & 15 & Experiment \\
\hline H9 & Male & 70 & AACG & 88 & 8 & Experiment \\
\hline $\mathrm{H} 10$ & Female & 72 & AACG & 95 & 8 & Experiment \\
\hline $\mathrm{H} 11$ & Female & 70 & AACG & 97 & 22 & Experiment \\
\hline H12 & Female & 63 & AACG & 99 & 36 & Experiment \\
\hline $\mathrm{H} 13$ & Female & 56 & AACG & 91 & 34 & Experiment \\
\hline H14 & Female & 63 & AACG & 98 & 35 & Experiment \\
\hline H15 & Male & 70 & AACG & 82 & 15 & Experiment \\
\hline H16 & Female & 67 & AACG & 86 & 26 & Validation \\
\hline H17 & Female & 59 & AACG & 94 & 48 & Validation \\
\hline H18 & Female & 62 & AACG & 88 & 10 & Validation \\
\hline H19 & Female & 51 & AACG & 95 & 13 & Validation \\
\hline $\mathrm{H} 2 \mathrm{O}$ & Female & 62 & AACG & 92 & $T+2$ & Validation \\
\hline H21 & Male & 72 & AACG & 86 & 44 & Validation \\
\hline H22 & Female & 57 & AACG & 98 & 50 & Validation \\
\hline $\mathrm{H} 23$ & Female & 63 & AACG & 85 & 23 & Validation \\
\hline $\mathrm{H} 24$ & Female & 58 & AACG & 94 & 15 & Validation \\
\hline H25 & Female & 61 & AACG & 98 & 35 & Validation \\
\hline L1 & Female & 80 & AACG & 0 & 25 & Experiment \\
\hline L2 & Female & 70 & AACG & 0.59 & 14 & Experiment \\
\hline L3 & Female & 79 & AACG & 18 & $\mathrm{~T}+2$ & Experiment \\
\hline L4 & Female & 61 & AACG & 0 & 32 & Experiment \\
\hline L5 & Female & 81 & AACG & 20 & 50 & Experiment \\
\hline L6 & Female & 75 & AACG & 0 & 30 & Experiment \\
\hline L7 & Female & 78 & AACG & 5 & $\mathrm{~T}+2$ & Experiment \\
\hline L8 & Female & 50 & AACG & 23 & 15 & Experiment \\
\hline L9 & Male & 65 & AACG & 0 & $T+2$ & Experiment \\
\hline L10 & Female & 69 & AACG & 21 & 16 & Experiment \\
\hline L11 & Female & 76 & AACG & 24 & 40 & Experiment \\
\hline L12 & Male & 68 & AACG & 8 & 17 & Experiment \\
\hline L13 & Female & 66 & AACG & 27 & 45 & Experiment \\
\hline L14 & Female & 60 & AACG & 36 & 18 & Experiment \\
\hline L15 & Female & 56 & AACG & 35 & 55 & Experiment \\
\hline L16 & Female & 68 & AACG & 8 & 17 & Experiment \\
\hline L17 & Female & 65 & AACG & 0 & $T+2$ & Validation \\
\hline L18 & Female & 65 & AACG & 0 & $\mathrm{~T}+2$ & Validation \\
\hline L19 & Female & 72 & AACG & 4 & 20 & Validation \\
\hline L20 & Female & 66 & AACG & 0 & 35 & Validation \\
\hline L21 & Female & 60 & AACG & 0 & 14 & Validation \\
\hline L22 & Female & 60 & AACG & 34 & 16 & Validation \\
\hline L23 & Male & 70 & AACG & 5 & 7 & Validation \\
\hline L24 & Female & 80 & AACG & 0 & $T+3$ & Validation \\
\hline L25 & Female & 66 & AACG & 6 & 56 & Validation \\
\hline L26 & Female & 73 & AACG & 9 & & Validation \\
\hline L27 & Female & 86 & AACG & 0 & & Validation \\
\hline
\end{tabular}

$\mathrm{VFI}$, visual field index; IOP, intraocular pressure. 


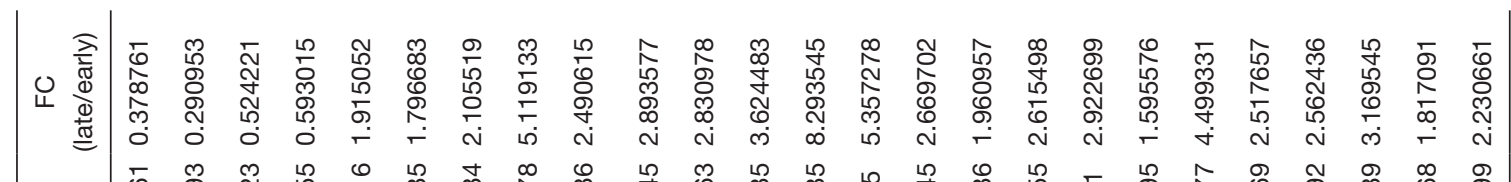

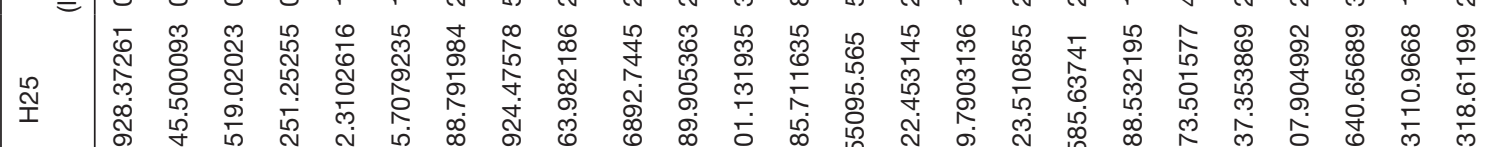

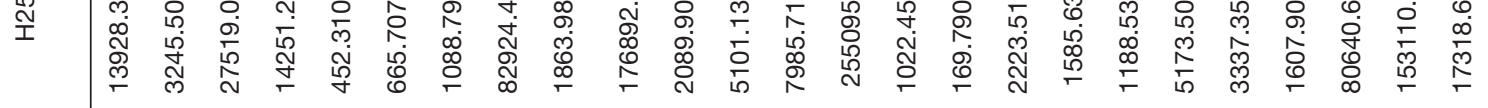

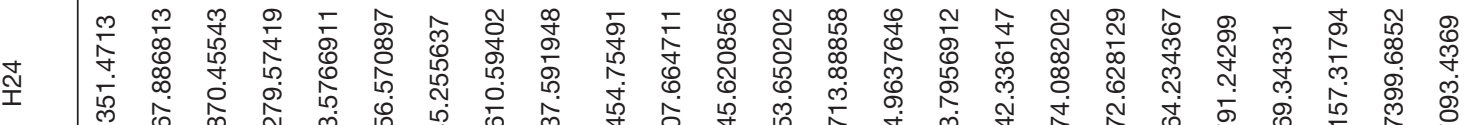

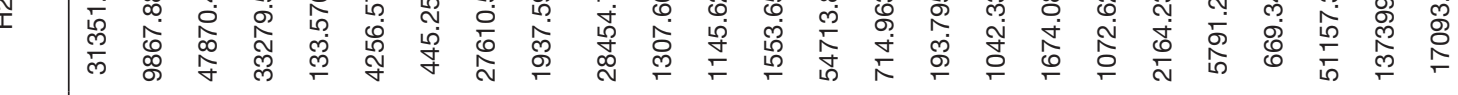

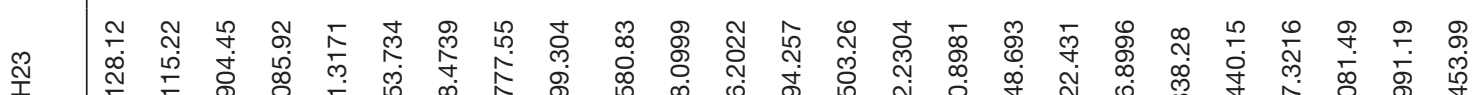

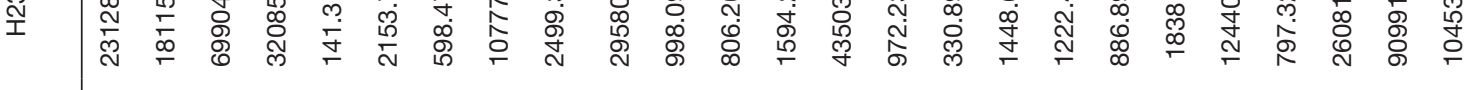

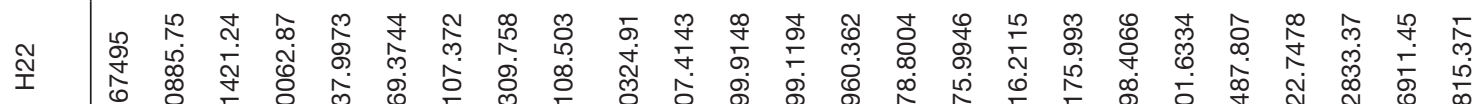
b

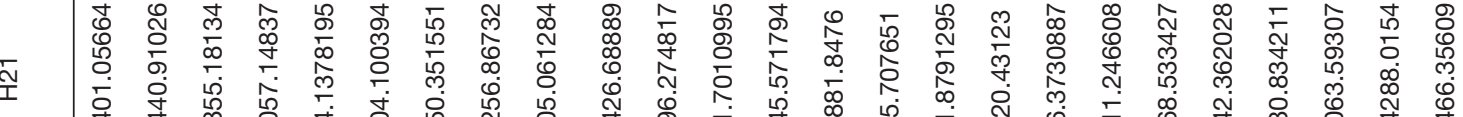

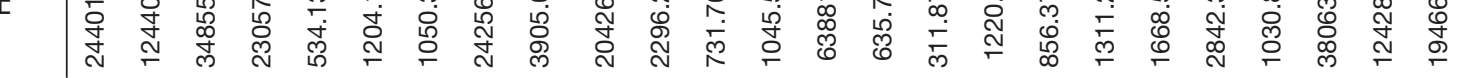

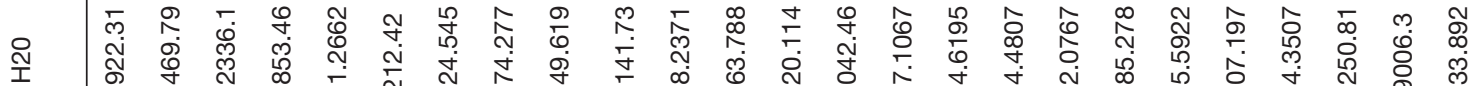
焉

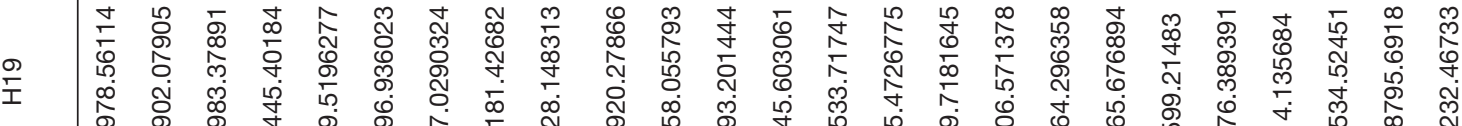

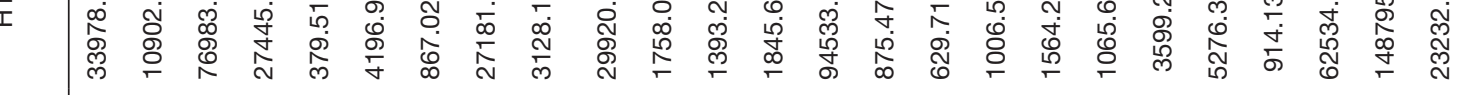

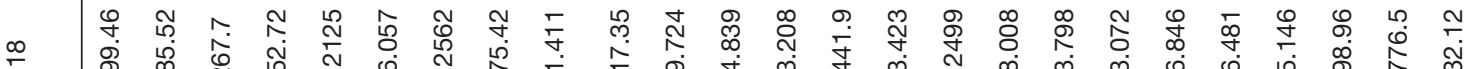

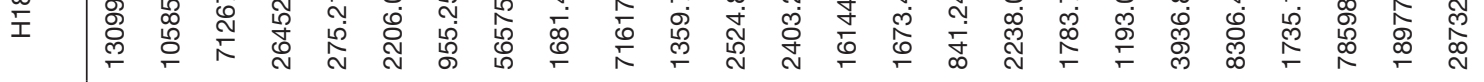

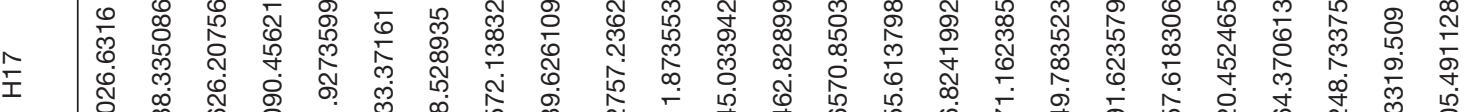

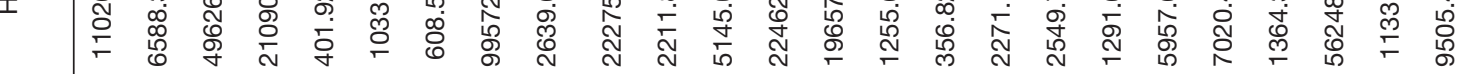

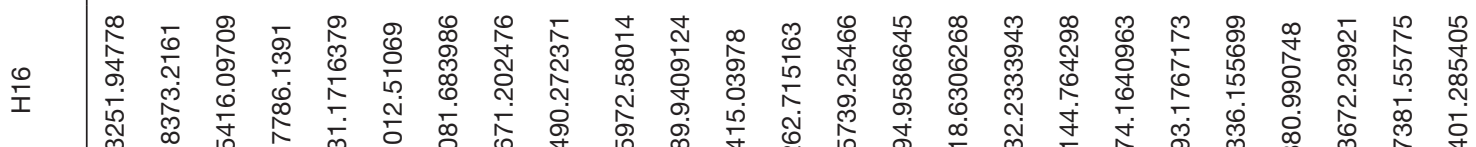

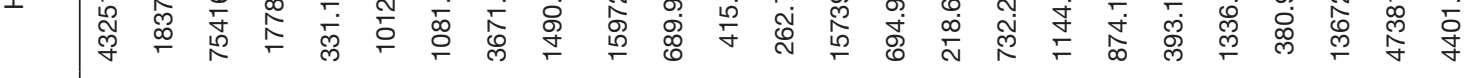

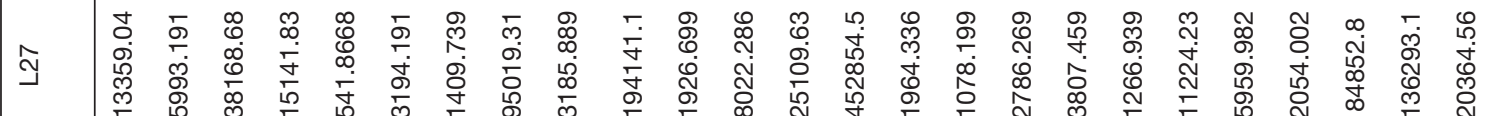

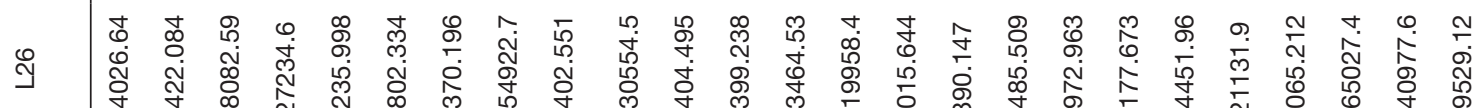

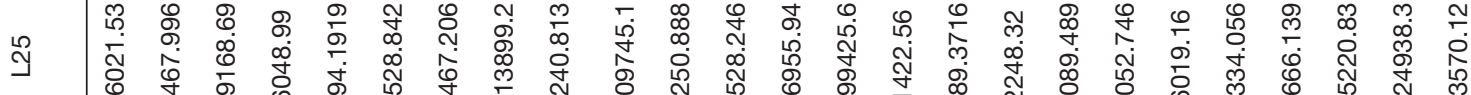

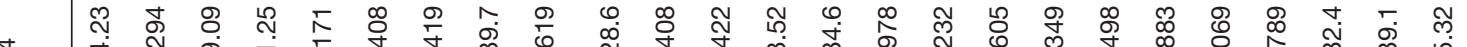

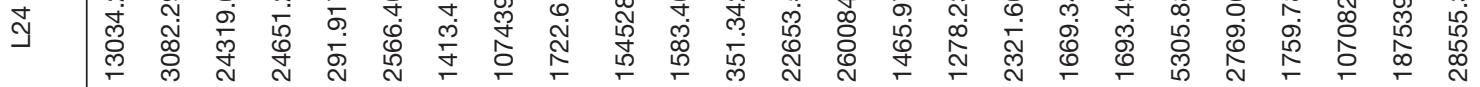

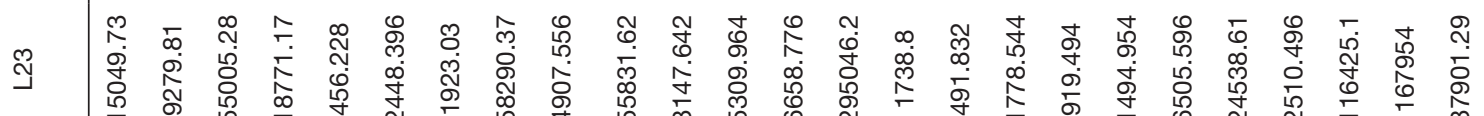

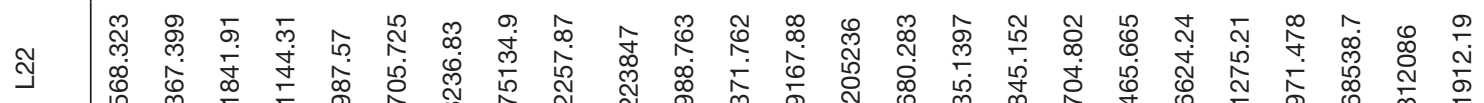

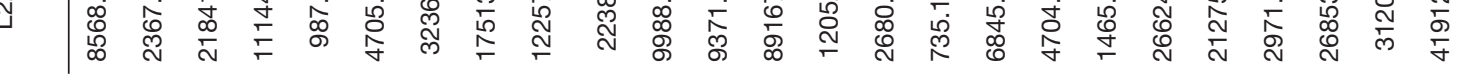

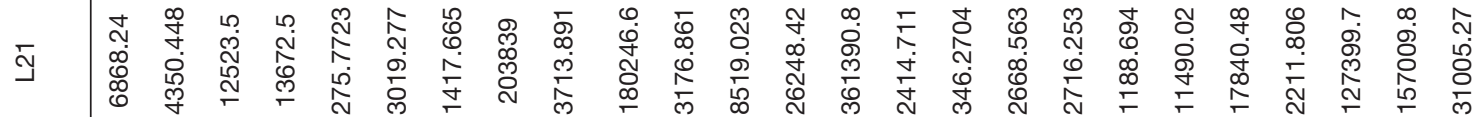
-

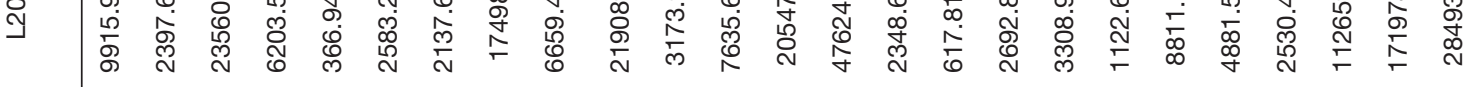

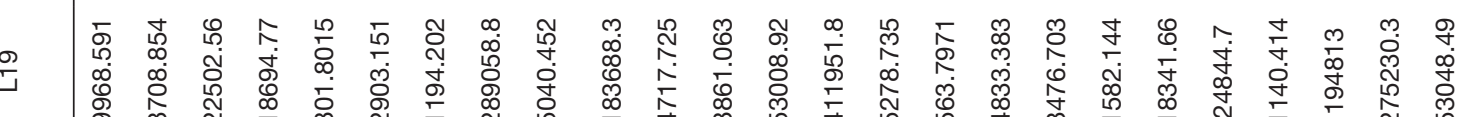

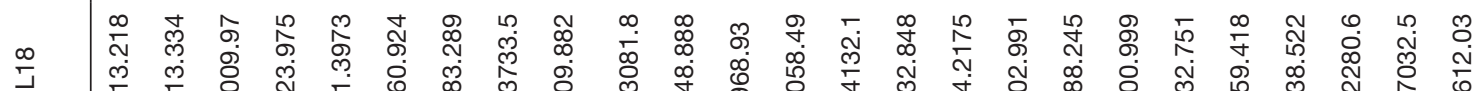

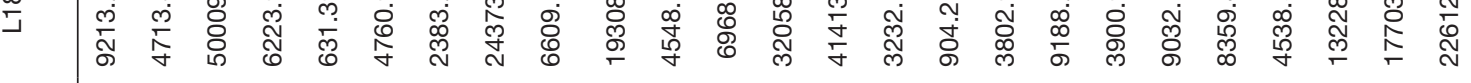

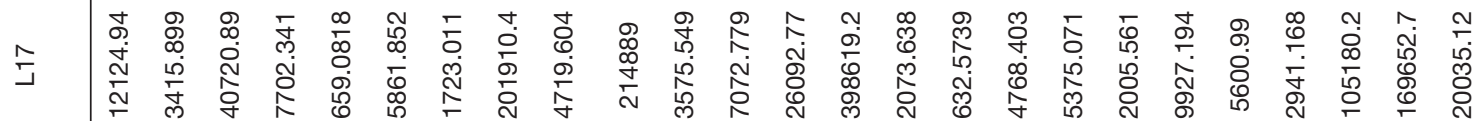

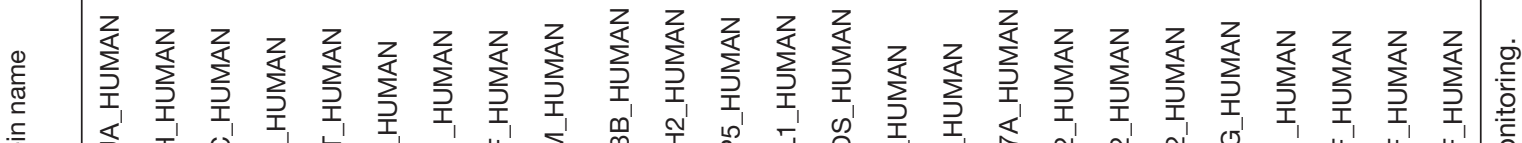

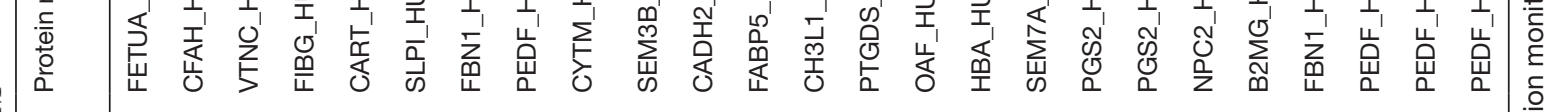

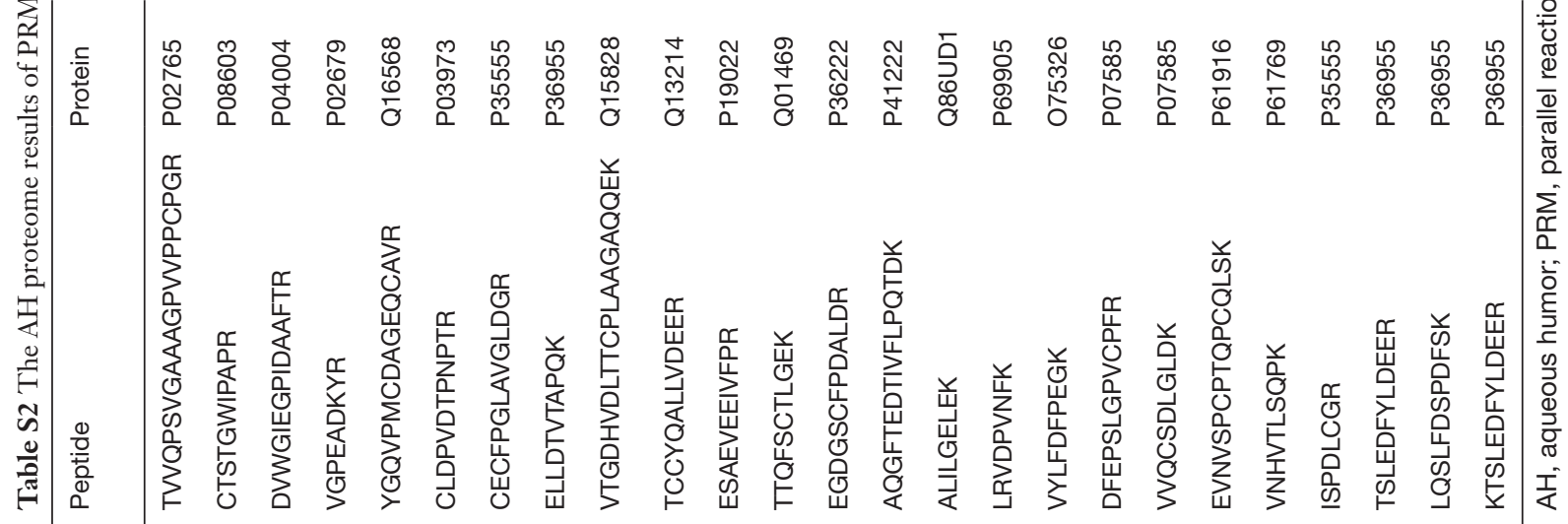

